\title{
Estimation and Comparison of Treasury Auction Formats when Bidders are Asymmetric
}

\author{
Olivier Armantier*
}

\author{
Erwann Sbaï ${ }^{\dagger}$
}

May 2003

\begin{abstract}
The structural parameters of a share-auction model accounting for asymmetry across bidders, as well as supply uncertainty are estimated with a sample of French Treasury auctions. We find evidence of both informational and risk aversion asymmetries between bidders. A counter-factual analysis also suggests that, in the context of the French Treasury auctions, a shift from the discriminatory to the uniform-price format would simultaneously benefit the French Treasury and the auctions' participants.
\end{abstract}

*Department of Economics, State University of New York at Stony Brook, Stony Brook, NY, 11794-4384. Email: olivier.armantier@sunysb.edu.

†GREMAQ, Université de Toulouse 1, 31000 Toulouse, France. Email:erwann.sbai@univtlse1.fr.

We are very grateful to Guillermo Caruana, Ali Hortaçsu, Soiliou Daw Namoro, Harry Paarsch, Nicolas Treich, Michaël Visser, James Wang, and Patrick Waelbroeck for insightful comments on earlier drafts. We are especially grateful to Jean-Pierre Florens for his help and support. Olivier Armantier would like to thank the Universitat Pompeu Fabra, and the Institut d'Analisi Economica where part of this research was conducted. We also thank seminar participants at the Université de Toulouse, Universitad Carlos III, and the ECARES at the Université Libre de Bruxelles. All remaining errors are ours. 


\section{Introduction}

Since the early 1960s, economists have debated the most appropriate auction mechanism to sell Treasury securities. As we shall see, the various theoretic models proposed, and the numerous empirical analysis conducted, have not produced an unambiguous conclusion. In fact, two recent papers by Wang and Zender (2002), and Ausubel and Cramton (2002), suggest that a theoretical ranking of auction formats may be impossible in general. The authors actually conclude that the superiority of an auction mechanism may only be determined empirically on a case-by-case basis. Moreover, economic analyses of Treasury auctions are typically based on the empirically questionable assumption that participants are symmetric with respect to resources, information available, and aversion to risk. The object of the present paper is to estimate a structural model with a sample of French Treasury auctions to test whether participants are symmetric, and to determine which auction format is preferable in this context.

At a Treasury auction, a specific type of security is sold to several accredited financial institutions. The bidders submit simultaneously a sealed bid consisting of a demand schedule. A bid therefore specifies the number of units of the security requested at each possible price. The market-clearing price, also known as the stop-out-price, matches aggregate demand with the available supply of security. Two basic formats are typically considered: at discriminatory auctions, the most frequently used, the highest bids are filled at the bided price until supply is exhausted; at uniform-price auctions, bidders pay the stop-out-price for all units they requested at prices exceeding the stop-out-price.

Beginning with Wilson (1979), Treasury auctions have been typically modelled as common-value auctions in which symmetric bidders compete for a share of the quantity supplied. ${ }^{1}$ In practice, however, a broad range of financial institutions participate in Treasury auctions, and the symmetry assumption may be questioned. In France, for instance, a small group a large banks submits most bids, and controls roughly $60 \%$ of the securities allocated. ${ }^{2}$ As we shall see, ignoring

\footnotetext{
${ }^{1}$ Anton and Yao (1992), as well as Hortaçsu (2002a), are exceptions as they consider that treasury auctions have essentially a private-values component, and that bidders submit discrete demand functions.

${ }^{2}$ This type of asymmetries are not specific to the French Treasury auctions. For instance, Hortaçsu (2002a) finds that 20 (50) out of 134 participants entered 20 (less than 10) out of the 27 Turkish Treasury auctions in his sample. In addition, Hortaçsu notes that "the top 5 bidders capture $30 \%$ evenly, and the top 15 capture about $70 \%$ of the issues." Comparable asymmetries have been observed in Treasury auctions over the world (e.g. Umlauf 1993 in Mexico, Malvey
} 
the presence of asymmetries across participants may have serious consequences on optimal bidding behavior, and it may also affect the ranking of the auction formats in terms of the revenue generated by the Treasury. Indeed, our theoretic model suggest that risk averse, and/or less-informed bidders become relatively more aggressive at uniform-price auctions, since they do not have to pay their bid. This, in turns, affects the allocation of the security among the different types of bidders, as well as the revenue raised by the Treasury. Our results, however, confirm that the superiority of an auction format cannot be established in general in this asymmetric environment, as it depends on the structural parameters underlying the model. In other words, as suggested by Ausubel and Cramton (2002), the choice between the uniform-price and discriminatory auction formats in the presence of asymmetric bidders remains essentially an empirical question, that we need to address econometrically in the specific case of the French Treasury auctions.

Our first objective is to develop a structural model to test whether the participants in the French Treasury auctions i) have access to different sources of information regarding the value of the security for sale, and ii) have different levels of risk aversion. To do so, we generalize the common-value share auction model of Wang and Zender (2002), in which the quantity for sale is not perfectly known at the time of the auction (possibly as the result of non-competitive bids), to account for informational and risk aversion asymmetries across bidders. ${ }^{3}$ This generalized model cannot be solved analytically, and we have to rely on numerical techniques to approximate the untractable Bayesian Nash equilibrium (hereafter BNE). The structural parameters underlying our Treasury auction model are then estimated using an original application of the method of simulated moments to the estimation of games of incomplete information. This method enables in particular to take advantage of all the information available in the sample. The estimated parameters suggest that the participants in French Treasury auctions may be divided in two distinct groups. One group consisting mostly of smaller financial institutions, characterized by a higher level of risk aversion, and receiving

and Archibald 1998 in the US, and Bjonnes 2001 in Norway).

${ }^{3}$ Non-competitive bids consist only in a (limited) quantity demanded by accredited financial institutions that will be filled systematically by the auctioneer. The price paid by noncompetitive bidders is the same, but it is unknown at the time they submit their bids. Depending upon the auction rule, the price is either equal to the stop-out-price, or a function of the prices paid by the competitive bidders in the subsequent auction. The quantities demanded by non-competitive bidders are only revealed after the auction. As a result, competitive bidders do not known at the time of the auction, the remaining quantity that will be supplied to them. 
significantly noisier signals about the true value of the security.

Finally, Monte Carlo simulations are conducted to compare the discriminatory and uniform-price formats. We find that, in the context of the French Treasury auctions, the uniform-price format would simultaneously increase (on average) the revenue of the Treasury, and the utility of both types of participants. This result may be explained by the combination of two factors. First, the uniformprice auction significantly reduces the variance of the bidders profits. As a result, the expected utility of the participants (who are risk averse) increases under the uniform pricing rule, even though the expected profits of some bidders may slightly diminish. Second, as small bidders become more aggressive, the average price paid by a bidder (regardless of type) for a unit of the security increases under the uniform-price format. Consequently, the total revenue of the Treasury rises on average compared to the discriminatory format.

The paper is structured as follows: in section 2, we summarize the literature relevant to the present paper; the share auction model accounting for asymmetry between participants and supply uncertainty is presented in section 3; the general technique to approximate untractable Bayesian Nash Equilibria is introduced in section 4, and it is applied to the share auction model in section 5; section 6 briefly describes the market for the French Treasury securities, as well as our sample of data; in section 7 we complete the specification of the structural share auction model; the econometric estimation technique is outlined in section 8; the results of the structural estimation of the French Treasury auctions are analyzed in section 9; section 10 compares the discriminatory and uniform-price auction formats; finally, section 11 concludes.

\section{Related Literature}

Beginning with Friedman (1960), the choice between the uniform-price and discriminatory auction formats has been often debated among economists. ${ }^{4}$ Uniformprice auctions were initially presented as the revenue maximizing mechanism to sell Treasury securities. The argument offered was that discriminatory auctions reduce competition by discouraging less informed bidders from participating, and therefore facilitate collusion. ${ }^{5}$ These contentions were later on disputed on the ba-

\footnotetext{
${ }^{4}$ For surveys of the literature on Treasury auctions, see Bikchandani and Huang (1993), Das and Sundaram (1996), Nandi (1997), or Klemperer (2000).

${ }^{5}$ Note that these early arguments were rather informal since the strategic nature of the Treasury auctions was typically ignored.
} 
sis of comparisons with single-unit auction models. However, building on the share auction model of Wilson (1979), Back and Zender (1993) demonstrated that conclusions drawn from single-unit auctions cannot be systematically extended to the multi-unit case. In particular, Back and Zender found that uniform-price auctions may have a continuum of undesirable collusive equilibrium, some of which yielding arbitrarily low revenue to the seller. More recently, Wang and Zender (2002) extended the share auction model to account for risk aversion, and random supply generated by the presence of non-competitive bids. Wang and Zender demonstrate that the presence of random supply drastically reduces the set of implausible equilibria. $^{6}$ In fact, they show in an example that the uniform-price equilibrium is unique when supply is random. More importantly, Wang and Zender find that it is in general impossible to compare the uniform and discriminatory pricing rules in terms of the revenue raised by the Treasury. Adopting a slightly different approach, Ausubel and Cramton (2002) find as well that the theory does not enable to rank unambiguously the two auction formats. In fact, they conclude that "determining the better pricing rule is necessarily an empirical question." The superiority of an auction format, in the context of the French Treasury, therefore depends on specific empirical factors, such as the bidders' individual valuation of the Treasury securities, and/or their level of risk aversion.

From an empirical perspective, two approaches should be distinguished: the reduced-form and the structural approach. The reduced-form approach has been the most frequently applied to rank auction formats in terms of revenue. After the 1992 Salomon scandal, the US Treasury shifted momentarily from the discriminatory to the uniform-price format to sell some of its securities. ${ }^{7}$ This natural experiment prompted a series of reduced-form analysis to evaluate the consequences of such a decision. For instance, Simon (1994) estimated that the US government lost large amounts of money by modifying the auction format, while Mester (1995), Nyborg and Sundaresan (1996), as well as Malvey and Archibald (1998) found that the uniform-price auction had a positive, but often insignificant effect on the Treasury revenue. Other reduced-form analyses conducted after natural experiments in different countries (e.g., Umlauf 1993 in Mexico, Tenorio 1993 in Zambia, or Berg, Boukai and Landsberger 1999 in Norway), seem to give a slight edge to the uniform-price format. However, conclusions from the reduced form approach are often considered too inconsistent to contribute unambiguously

\footnotetext{
${ }^{6} \mathrm{~A}$ similar argument has been advanced by Klemperer and Meyer (1989) who found that demand uncertainty in procurement auctions reduces the set of equilibria to a singleton.

${ }^{7}$ See Jegadeesh (1993) for details.
} 
to the debate pertaining to the choice of Treasury auction mechanism. In fact, the results in Malvey and Archibald (1998) suggest that reduced-form analysis following natural experiments may not be the most appropriate approach to assess the superiority of an auction format. Indeed, the authors note that after shifting to the uniform pricing rule, the auctions' outcomes became much more volatile from one auction to the next. Because of this added noise, a reduced-form analysis may not be able to identify the revenue differences between auction formats, especially if these differences are small.

The second empirical approach has been adopted only recently, following the developments in the estimation of structural models of incomplete information. ${ }^{8}$ This approach appears most promising to address the question of auction format in specific contexts, such as the French Treasury auctions, in which no natural experiment has been conducted. Hortaçsu (2002a) adopts such a structural approach to estimate non-parametrically a symmetric private-values model, in which the quantities demanded belong to a finite grid. Considering a sample from the Turkish Treasury auctions, the author finds that the discriminatory format yields higher revenues than the uniform-price mechanism would. Fevrier, Preguet and Visser (2002) estimate with a relatively small sample from the French Treasury the share auction model originally proposed by Wilson (1979). They find that the uniform-price format would have lowered by $8 \%$ (on average) the Treasury's revenue. Finally, Castellanos and Oviedo (2002) applies the structural approach developed by Fevrier et al. (2002) to a sample of Mexican Treasury auctions. In contrast with the previous studies, Castellanos and Oviedo find that a uniform price auction would increase the Mexican Treasury's revenue by $1.44 \%$. The authors explain this result by a higher estimated variation in the Mexican participants signals about the true value of the security. However, the pertinence of the structural approach may be questioned as it relies on simplifying, but often empirically questionable assumptions (e.g., symmetry and/or risk neutrality), in order to solve the theoretic model analytically, or to enable the application of an econometric estimator.

The present paper, although based on the structural approach, differs in several aspects from the three previously mentioned analyses. First, unlike Hortaçsu (2002a), we consider a common-value model with continuous bid functions. Both

\footnotetext{
${ }^{8}$ See e.g., Paarsch (1992), Donald and Paarsch (1993,1996), Laffont, Ossard and Vuong (1995), Guerre, Perrigne and Vuong (2000), as well as Florens, Protopopescu and Richard (2002).
} 
assumptions are generally considered reasonable to describe Treasury auctions. ${ }^{9}$ Second, our model accounts for risk aversion and demand uncertainty. As we shall see, these elements better describe the French Treasury auctions, they eliminate non-realistic equilibria, and they have a significant impact on the ranking of auction mechanisms. Third, we explicitly account for informational and risk aversion asymmetries in the theoretic model. As previously mentioned, the symmetry assumption is empirically questionable in most Treasury auctions around the world. ${ }^{10}$ Fourth, instead of simplifying the model for tractability purposes, we rely on approximation techniques to solve the complex theoretic models. Finally, we apply an alternative estimation approach that enables to take advantage of all the information available in the sample.

\section{A Share Auction Model with Asymmetric Bidders and Risk Aversion}

The model adopted is largely inspired from Wang and Zender (2002). A specific quantity of a perfectly divisible good is for sale to $N$ competitive bidders $(N \geq 2)$ each maximizing his ex-ante expected utility. ${ }^{11}$ A bidder's decision to participate in the auction (i.e., to submit a competitive bid) is assumed to be exogenous and common knowledge. The quantity supplied to the bidders by the auctioneer is unknown at the time of the auction. ${ }^{12}$ From the players perspective, the quantity supplied is a random variable $Q \in \Theta_{Q}$, with cumulative distribution function (c.d.f.) $G(Q)$. The actual value $V \in \Theta_{V}$ of the good is the same to each bidder,

\footnotetext{
${ }^{9}$ See e.g., Wilson (1979), Das and Sundaram (1996), Wang and Zender (2002), as well as Ausubel and Cramton (2002).

${ }^{10}$ Hortaçsu (2002a) also considers the effect of a potential distributional asymmetry. He finds that the presence of informational asymmetry would not modify the overall nature of the results he obtained under the symmetry assumption.

${ }^{11}$ Following most of the Treasury auction literature, non-competitive bids are assumed to result from exogenous decisions made prior to the auction. Therefore, non-competitive bidding will not be explicitly modelled, and it is assumed to affect only the quantity available to competitive bidders. The competitive bidders will be referred, in the remainder, as the "bidders", the "players", or the "participants" unless mentioned otherwise

${ }^{12}$ In practice, the quantity available to competitive bidders is uncertain because noncompetitive bids, which are frequently used in French Treasury auctions, are only revealed after the auction. In addition, some of the uncertainty also originates from the fact that the French Treasury announces only a bracket for the total quantity of securities to be supplied to competitive and non-competitive bidders.
} 
but it is unknown at the time of the auction. The c.d.f. of the true value, denoted $F_{0}(V \mid \delta)$, depends on a parameter $\delta$ to be estimated.

We consider that two groups of asymmetric bidders, respectively composed of $N_{1}$ and $N_{2}$ bidders $\left(N_{1}+N_{2}=N\right)$, participate in the auction. ${ }^{13}$ Bidders within a given group are symmetric, but bidders are asymmetric across groups. To derive this asymmetric model, we will therefore consider a representative bidder in each of the two groups. Bidder $i$ in group $l=1,2$ receives a signal, $s_{i, l} \in \Theta_{S}$ containing some private information about the value of the good. This signal is generated from a conditional distribution with c.d.f. $F_{l}\left(s_{i, l} \mid V, \sigma_{l}\right)$, where $\left(\sigma_{1}, \sigma_{2}\right)$ are parameters to be estimated. ${ }^{14}$

After bidder $i$ in group $l$ receives the private signal $s_{i, l}$, she submits a sealed bid. This bid consists of a schedule specifying the share of the good demanded $\varphi_{i, l}\left(p, s_{i, l}\right)$ for any price $p>0$. The demand schedules are assumed to be (piecewise) continuously differentiable. The market clearing price $p^{0}$ is defined as the non-negative price at which aggregate competitive demand equals total supply:

$$
\sum_{i=1}^{N_{1}} \varphi_{i, 1}\left(p^{0}, s_{i, 1}\right)+\sum_{j=1}^{N_{2}} \varphi_{j, 2}\left(p^{0}, s_{j, 2}\right)=Q \quad \text { given } \quad p^{0} \geq 0
$$

At Treasury auctions, the above price is often called the stop-out-price. Winning bids are those submitted for prices greater than the stop-out-price. In other words, bidder $i$ in group $l$ receives a quantity $\varphi_{i, l}\left(p^{0}, s_{i, l}\right)$. In order to derive the equilibrium strategies for both auction formats simultaneously, we adopt the notation of Viswanathan and Wang (2000), and denote the payment of bidder $i$ in group $l$ as

$$
p^{0} \varphi_{i, l}\left(p^{0}, s_{i, l}\right)+\tau \int_{p_{0}}^{p_{i}^{\max }} \varphi_{i, l}\left(p, s_{i, l}\right) d p
$$

where $p_{i}^{\max }$ is the highest price for which bidder $i$ 's demand is strictly positive. Within this formulation, $\tau=0$ corresponds to the price paid under the uniform-

\footnotetext{
${ }^{13}$ The methodology developed below trivially generalizes to a larger number of asymmetric groups. Interviews with representants of the French government in charge of conducting the auctions indicated that participants in French Treasury auctions could essentially be divided in two distinct groups.

${ }^{14} \mathrm{We}$ assume in the remainder that the distributions of the private signals, and the distributions of the private signals conditional on the common value have the same support for both types of bidders.
} 
price format, and $\tau=1$ corresponds to the price paid under the discriminatory format.

The profit of bidder $i$ in group $l$ may then be written as

$$
\Pi_{i, l}\left(\varphi_{i, l}(\cdot), p^{0}, V, s_{i, l}\right)=\left(V-p^{0}\right) \varphi_{i, l}\left(p^{0}, s_{i, l}\right)-\tau \int_{p_{0}}^{p_{i}^{\max }} \varphi_{i, l}\left(p, s_{i, l}\right) d p
$$

To account for risk aversion, we assume that bidder $i$ in group $l$ has a CARA utility function of the form

$$
U_{i, l}\left(\varphi_{i, l}(\cdot), p^{0}, V, s_{i, l}, \lambda_{l}\right)=-\exp \left[-\lambda_{l} \Pi_{i, l}\left(\varphi_{i, l}(\cdot), p^{0}, V, s_{i, l}\right)\right],
$$

where $\lambda_{l}>0$ is the constant level of absolute risk aversion for players in group $l .^{15}$ We adopt the CARA specification because, unlike other specifications often used with private-values auctions, it enables one to optimize an individual's utility without requiring to know his wealth. In addition, the CARA specification is well suited for common-value auctions as the utility remains defined for any gain and loss. Note however, that the absolute risk aversion level of an individual is typically considered to vary with its wealth. In lack of full information regarding bidders' identity and wealth, we assume that auctions' profits do not significantly affect the wealth of the participants. In other words, $\lambda_{l}$ will be assumed to remain constant over the period spanned by our sample of French Treasury auctions.

\section{Constrained Strategic Equilibrium}

To the best of our knowledge, the asymmetric share auction model we just presented cannot be solved analytically. Approximation methods therefore appear to be the only feasible approach to solve the model without imposing simplifying assumptions. ${ }^{16}$ We adopted the Constrained Strategic Equilibrium (hereafter CSE) technique developed by Armantier, Florens and Richard (2002) (hereafter AFR) to approximate untractable BNE. As we shall see, this approach appears to

\footnotetext{
${ }^{15}$ More than the bank itself, we suspect that the bank's employee(s) in charge of bidding in Treasury auctions may exhibit risk aversion, as his job may depend on how he performs.

${ }^{16}$ Hortaçsu (2002b) also argues in favor of the use of approximations methods to solve Treasury auction models, and in particular discriminatory auction models, which are often analytically intractable. The approximation technique he adopts, although slightly different, relies on comparable principles as the method we now present.
} 
provide the proper combination of accuracy and computational speed necessary to solve and estimate the asymmetric French Treasury auction model. The CSE method is now summarized in the general framework of a game of incomplete information.

There are $N$ players, each endowed with a privately known 'signal' $\xi_{i} \in \Xi_{i}$ where $\Xi_{i} \subset \mathbb{R}^{p}$. The signals $\xi=\left(\xi_{1}, \ldots, \xi_{N}\right)$ are drawn from a joint distribution with cumulative distribution function $F(\xi)$. After observing their own signal, players select simultaneously an action $x_{i} \in X_{i}$, where $X_{i}$ denotes the set of possible actions player $i$ can take. Players are endowed with individual Von NeumanMorgenstern utility functions $U_{i}(x, \xi)$, where $x=\left(x_{1}, \ldots, x_{N}\right)$. A strategy profile $\varphi=\left(\varphi_{1}, \ldots, \varphi_{N}\right)$, where $\varphi \in H$, and $H=\prod_{i=1}^{N} H_{i}$ is the set of possible strategies, is defined by $N$ measurable functions transforming signals into actions

$$
\begin{aligned}
\varphi_{i} & : \quad \Xi_{i} \rightarrow X_{i} \\
\xi_{i} & \rightarrow \quad x_{i}=\varphi_{i}\left(\xi_{i}\right), \quad i=1, \ldots, N .
\end{aligned}
$$

The joint distribution $F$, the utility functions $\left\{U_{i}\right\}_{i=1, \ldots N}$, and the sets of strategies $\left\{H_{i}\right\}_{i=1, \ldots N}$ are assumed to be common knowledge.

The definition of a CSE parallels that of a BNE in strategic form, except that strategies are restricted to subsets $H_{i}^{(k)} \subset H_{i}$, where $k$ is a scalar to be defined below. A CSE in the set of strategies $H^{(k)}=\prod_{i=1}^{N} H_{i}^{(k)}$ is therefore a strategic implementation of the game $\varphi_{C S E}^{(k)}=\left(\varphi_{1, C S E}^{(k)}, \ldots, \varphi_{N, C S E}^{(k)}\right)$ with $\varphi_{C S E}^{(k)} \in H^{(k)}$, whereby the $\varphi_{i, C S E}^{(k)}$ 's are mutually best responses in the strategic form game

$$
\widetilde{U}_{i}\left(\varphi_{i, C S E}^{(k)}, \varphi_{-i, C S E}^{(k)}\right) \geq \widetilde{U}_{i}\left(\varphi_{i}^{(k)}, \varphi_{-i, C S E}^{(k)}\right) \quad \forall \varphi_{i}^{(k)} \in H_{i}^{(k)}, \forall i=1, \ldots, N
$$

where $\widetilde{U}_{i}(\varphi)=E_{\xi}\left[U_{i}(\varphi(\xi), \xi)\right]$. The CSE may also be expressed as a fixed point solution of the constrained best response correspondence

$$
\varphi_{i, C S E}^{(k)} \in \underset{\varphi_{i}^{(k)} \in H_{i}^{(k)}}{\operatorname{Arg} \max } \widetilde{U}_{i}\left(\varphi_{i}^{(k)}, \varphi_{-i, C S E}^{(k)}\right) \quad \forall i=1, \ldots, N \quad .
$$

The determination of this fixed point is greatly simplified when the strategies in $H_{i}^{(k)}$ may be parametrized by a vector of dimension $k, d_{i}^{(k)} \in D_{i}^{(k)} \subset \mathbb{R}^{k}$. This approach provides a major computational advantage, since it requires to optimize 
over a finite set of parameters rather than an infinite set of functions as it is the case with BNE.

AFR determine conditions for the existence of a CSE. The authors also show in a broad class of games of incomplete information, that if the family of constrained sets $\left\{H^{(k)}\right\}_{k=1, \ldots, \infty}$ is such that i) $H^{(k)} \subset H^{(k+1)}$ and ii) $\cup_{k \geq 1} H^{(k)}$ is dense in $H$, then any sequence of CSEs $\left\{\varphi_{C S E}^{(k)}\right\}_{k=1, \ldots, \infty}$ approximates a BNE of the game. In addition, if $\left\{\varphi_{C S E}^{(k)}\right\}_{k=1, \ldots, \infty}$ constitutes a convergent sequence, and $\varphi_{C S E}^{(k)}$ is the unique CSE in $H^{(k)}(\forall k>0)$, then the sequence of CSEs converges toward the unique BNE of the game. Finally, AFR (2002) propose a powerful algorithm, based on Monte Carlo simulations, to derive the CSE numerically at a high level of generality.

Four criteria have been proposed to evaluate in practice the quality of the CSE approximation, and to decide when to stop the numerical approximation procedure consisting in calculating a CSE in expanding constrained sets $H^{(k)}{ }^{17}$ The first criterion is similar to traditional approximation stopping rules, as it verifies whether the sequence of CSEs converges: $C_{1}(k, t)=\left\|\varphi_{C S E}^{(k)}-\varphi_{C S E}^{(k+t)}\right\|$. The next two criteria compares the CSE to $\Phi_{B R}\left(\varphi_{C S E}^{(k)}\right)$, its best response in the unconstrained set of strategies $H$, both in terms of distance $C_{2}(k)=\left\|\varphi_{C S E}^{(k)}-\Phi_{B R}\left(\varphi_{C S E}^{(k)}\right)\right\|$, and expected utility $C_{3}(k)=\left\|\widetilde{U}\left(\varphi_{C S E}^{(k)}\right)-\widetilde{U}\left(\Phi_{B R}\left(\varphi_{C S E}^{(k)}\right), \varphi_{C S E}^{(k)}\right)\right\| \cdot{ }^{18}$ In particular, $C_{3}(k)$ close to zero indicates that players have little incentive to deviate from the CSE to adopt a more elaborated (unconstrained) strategy. Finally, the CSE is reinterpreted in the fourth criteria as an actual BNE in a perturbed game in which private signals are generated from a distribution $F_{\varphi_{C S E}^{(k)}}$, rather than the actual distribution $F$. The approximation quality is then evaluated by the distance between the original and perturbed games, as measured by $C_{4}(k)=\left\|F-F_{\varphi_{C S E}^{(k)}}\right\|$. When the distribution $F$ is estimated, the criterion $C_{4}(k)$ also provides some in-

\footnotetext{
${ }^{17}$ See AFR (2002) for details related to the evaluation of these criteria with Monte Carlo simulations in practical applications.

${ }^{18}$ More precisely, $\Phi_{B R}\left(\varphi_{C S E}^{(k)}\right)$ is a vector of dimension $N$, such that $\Phi_{B R, i}\left(\varphi_{C S E}^{(k)}\right)$ is the best response of player $i(i=1, \ldots, N)$ in the unconstrained set of strategy $H_{i}$, when his opponents use the CSE $\varphi_{C S E,-i}^{(k)}$. Moreover, the ith component of vector $\widetilde{U}\left(\Phi_{B R}\left(\varphi_{C S E}^{(k)}\right), \varphi_{C S E}^{(k)}\right)$ is in fact $\widetilde{U}_{i}\left(\Phi_{B R, i}\left(\varphi_{C S E}^{(k)}\right), \varphi_{C S E,-i}^{(k)}\right)$.
} 
formation on the specification error due to the use of the approximation $\varphi_{C S E}^{(k)}$ instead of the actual BNE in the structural econometric model. Indeed, $C_{4}(k)$ sufficiently close to 0 indicates that the specification error is marginal, since a consistent estimation of $F_{\varphi_{C S E}^{(k)}}$ with the correctly specified structural model (i.e., based on the corresponding $\operatorname{BNE} \varphi_{C S E}^{(k)}$ ), would have yielded an estimate essentially similar to the original distribution $F$.

The CSE approach has been successfully applied to the theoretical and empirical analysis of several complex auction models with untractable BNEs. For instance, AFR (1998) analyze a procurement from the French aerospace industry, in which the good for sale is allocated to the player bidding the lowest ratio of quality over price. AFR (2002) approximate a similar model under the additional assumption of bidders collusion, or informational asymmetry. AFR (2001) evaluate the welfare implications associated with the use of a complex redistributive allocation mechanism (known as the "Juste Retour") at European Spatial Agency procurements. Finally, Eklöf (2003) applies the CSE approach to estimate the social cost implied by the inefficient allocation of contracts in first-price-sealed-bid procurement auctions with asymmetric bidders.

In these applications, the constrained set $H^{(k)}$ was defined as a polynomial of degree $k$, or a piecewise linear function with $k$ breaking points. ${ }^{19}$ Intuitively, the CSE approach reduces in these cases to approximating any unconstrained strategy, and in particular any BNE, with a suitable polynomial or piecewise linear function. The criteria of convergence were used in these applications to decide the appropriate degree of the polynomial, or number of breaking points, that provided a sufficiently accurate approximation. It is important to note that, in empirical applications, the quality of the CSE approximation calculated with the estimated distribution may be arbitrarily precise. Indeed, the parameter $k$ and the dimension of the Monte Carlo simulation used to calculate the CSE numerically, are fully independent of the sample size.

AFR (2002), as well as Eklöf (2003), also show that the CSE approach typically outperforms alternative approximation methods (consisting in solving a set of differential or Euler equations) not only in terms of accuracy, but also in terms of computational speed. This latter aspect is crucial in the present context, since the subsequent structural estimation requires to evaluate the approximated equi-

\footnotetext{
${ }^{19}$ Although more sophisticated constrained strategies may be considered, we find that simple polynomials and piecewise linear functions i) provide very accurate approximations, ii) are numerically undemanding, iii) have appropriate properties to address the question of the CSE existence.
} 
librium for each auction in our sample an extremely large number of time (roughly $10^{12}$ time). Our experience with alternative approximations techniques suggests that they would have been inappropriately slow to estimate the French Treasury auction model. Moreover, unlike other forms of approximation, the CSE shares with the BNE the property of being strictly monotonic in a wide range of games. This characteristic is crucial in empirical applications, since the structural econometric estimation techniques previously mentioned require monotonic strategies. In other words, the CSE approach is fast, accurate, and robust, and it appears to be the most adequate approximation method for the structural estimation of the French Treasury auction model.

\section{CSE for Auctions of Shares}

Let us denote $\varphi_{i, l}^{(k)}\left(p, s_{i, l}, d_{i, l}\right)$, where $d_{i, l} \in \mathbb{R}^{k}$, the strategy of player $i$ in group $l$ within the constrained set $H^{(k)}$. The stop-out-price $p^{0}$ is then defined by the implicit equation

$$
B\left(p^{0}, s, d, Q\right)=\sum_{i=1}^{N_{1}} \varphi_{i, 1}^{(k)}\left(p^{0}, s_{i, 1}, d_{i, 1}\right)+\sum_{j=1}^{N_{2}} \varphi_{i, 2}^{(k)}\left(p^{0}, s_{j, 2}, d_{j, 2}\right)-Q=0
$$

where $d=\left(d_{1,1}, \ldots, d_{N_{1}, 1}, d_{1,2}, \ldots, d_{N_{2}, 2}\right)$. We can then write $p^{0}$ as a function $p^{0}(s, d, Q)$ of the strategies, the quantity available to competitive bidders, and the signals $s=\left(s_{1}, s_{2}\right)$, where $s_{l}=\left(s_{1, l}, \ldots, s_{N_{l}, l}\right)$ and $l=1,2$. The profit function of bidder $i$ in group $l$ becomes

$\Pi_{i, l}(d, V, s, Q)=\left(V-p^{0}(s, d, Q)\right) \cdot \varphi_{i, l}^{(k)}\left(p^{0}(s, d, Q), s_{i, l}, d_{i, l}\right)-\tau \int_{p_{0(s, d, Q)}}^{p_{i}^{\max }} \varphi_{i, l}^{(k)}\left(p, s_{i, l}, d_{i, l}\right) d p$

and her (unconditional) expected utility may then be written as

$$
\begin{gathered}
\widetilde{U}_{i, l}\left(d, \lambda_{l}\right)=-E_{Q, V, s}\left[\exp \left[-\lambda_{l} \Pi_{i, l}(d, V, s, Q)\right]\right] \\
=-\int_{\Theta_{Q}} \int_{\Theta_{V}} \int_{\Theta_{S}^{N}} \exp \left[-\lambda_{l} \Pi_{i, l}(d, V, s, Q)\right] d \Delta(Q, V, s),
\end{gathered}
$$

where $\Delta(Q, V, s)$ is the joint distribution of the quantity supplied, the true value $V$, and the vector of private signals $s$. 
We can then derive the first order conditions defining the constrained bestresponse of a representative player $i$ in group $l$ to her opponents strategy profile

$$
\frac{\partial}{\partial d_{i, l}} \widetilde{U}_{i, l}\left(d, \lambda_{l}\right)=\iint_{\Theta_{Q}} \int_{\Theta_{V}}\left\{\lambda_{\Theta_{S}^{N}} \exp \left[-\lambda_{l} \Pi_{i, l}(d, V, s, Q)\right] \cdot \frac{\partial}{\partial d_{i, l}} \Pi_{i, l}(d, V, s, Q)\right\} d \Delta(Q, V, s)=0
$$

where

$$
\begin{aligned}
\frac{\partial}{\partial d_{i, l}} \Pi_{i, l}(\cdot)= & (\tau-1) \frac{\partial}{\partial d_{i, l}} p^{0}(\cdot) \cdot \varphi_{i, l}^{(k)}(\cdot)+\left(V-p^{0}(\cdot)\right)\left(\frac{\partial}{\partial p} \varphi_{i, l}^{(k)}(\cdot) \frac{\partial}{\partial d_{i, l}} p^{0}(\cdot)+\frac{\partial}{\partial d_{i, l}} \varphi_{i, l}^{(k)}(\cdot)\right) \\
& -\tau\left(\frac{\partial}{\partial d_{i, l}} \Phi_{i, l}^{(k)}\left(p, s_{i, l}, d_{i, l}\right)_{\mid p=p_{i}^{\max }}-\frac{\partial}{\partial d_{i, l}} \Phi_{i, l}^{(k)}\left(p, s_{i, l}, d_{i, l}\right)_{\mid p=p_{0}}\right),
\end{aligned}
$$

$\Phi_{i, l}^{(k)}(\cdot)$ is the primitive of $\varphi_{i, l}^{(k)}(\cdot)$ with respect to $p, \frac{\partial}{\partial d_{i, l}} p^{0}(\cdot)=-\frac{\partial}{\partial d_{i, l}} B(\cdot)\left(\frac{\partial}{\partial p^{0}} B(\cdot)\right)^{-1}$, $\frac{\partial}{\partial d_{i, l}} B(\cdot)=\frac{\partial}{\partial d_{i, l}} \varphi_{i, l}^{(k)}(\cdot)$, and $\frac{\partial}{\partial p^{0}} B(\cdot)=\sum_{i=1}^{N_{1}} \frac{\partial}{\partial p^{0}} \varphi_{i, 1}^{(k)}\left(p^{0}, s_{i, 1}, d_{i, 1}\right)+\sum_{j=1}^{N_{2}} \frac{\partial}{\partial p^{0}} \varphi_{i, 2}^{(k)}\left(p^{0}, s_{j, 2}, d_{j, 2}\right)$.

In the remainder, we concentrate on pure strategy equilibria in which players within a group behave symmetrically. In other words, the CSE is such that $\varphi_{i, l, C S E}^{(k)}=\varphi_{l, C S E}^{(k)}$, or equivalently $d_{i, l, C S E}=d_{l, C S E}\left(\forall i=1, \ldots, N_{l}\right.$ and $\left.\forall l=1,2\right)$. Since the parameter $d_{l, C S E}$ is of dimension $k$, and since we can consider only a representative player in each group, the determination of the CSE reduces to finding the fixed point of a system of $2 k$ non-redundant first order conditions of the form (5.1). The integrals in this system of equations may be approximated with arbitrary precision by standard Monte Carlo techniques. For instance, the expectations may be replaced by empirical means of simulated points. However, given the relatively high dimension of the integrals involved, such an approach would be extremely time consuming. Instead, Quasi Monte Carlo techniques, developed to improve coverage, are used to increase the precision of the approximation, while relying on fewer number of simulations (see Judd 1998).

Moreover, note that the resolution of the system of non-linear equations leading to the CSE is not as complex as it first appears. Indeed, for an appropriate selection of constrained strategies, the expressions $\frac{\partial}{\partial p} \varphi_{i, l}^{(k)}(\cdot), \frac{\partial}{\partial d_{i, l}} \varphi_{i, l}^{(k)}(\cdot)$, $\frac{\partial}{\partial d_{i, l}} \Phi_{i, l}^{(k)}(\cdot)$ may be derived analytically, which considerably reduces the computational burden. In addition, the problem is more straightforward from a numerical perspective, than most of the traditional auction models (see e.g., AFR 2002). Indeed, the utility functions in traditional auction models are discontinuous in 
players actions and strategies. Consequently, smoothing techniques must be used to solve efficiently these problems numerically. In the present context, the utility functions are continuous which simplifies significantly the numerical integrations.

\section{The Market and the Data}

\subsection{The market}

Our sample consists of discriminatory auctions held for two types of French government securities, the OAT and the BTAN. The OAT are the government's long-term debt instruments with maturities ranging from seven to thirty years. The BTAN represent medium-term government debts with a maturity of either two or five years.

The timing of these auctions unfold as follows: auctions for OAT and BTAN are held respectively the first and the third Thursday of each month. Four business days before the auction, the "Agence France Trésor", which is in charge of conducting the auction, announces the details of the different "lines" to be auctioned. A line consists of either an OAT or a BTAN with specific characteristics including the nominal yield, the maturity, as well as a bracket for the volume of security (expressed in Euros) to be served to competitive and non-competitive bidders. Part of the announced Treasury security may then be traded on a primary (or "when-issued") market until the date of the auction by a limited number of authorized dealers.

Competitive bidders may submit a demand function. A quantity demanded is in fact an amount in Euros representing a share of the quantity sold by the Treasury. Prices are expressed as a percentage (formulated with two decimal digits) of the nominal value of the security (one Euro). ${ }^{20}$ Moreover, pre-qualified bidders may submit a non-competitive offer for any line, consisting in a (limited) amount that will be systematically served at a price equal to the (quantity weighted) average price of the awarded competitive bids. Bids by eligible institutions, for all lines to be auctioned that day, must be submitted either electronically or in sealed envelops at least 10 minutes prior to the auction.

Before the bids submitted are observed, the French Treasury sets the exact quantity that will be supplied to competitive and non-competitive bidders. ${ }^{21}$ Com-

\footnotetext{
${ }^{20}$ The Treasury securities are expressed in Euros since 1999. The 1998 auctions expressed in French Francs, were converted in Euros at the rate of 1 Euro for 6,55957 Francs.

${ }^{21}$ To the best of our knowledge, the French Treasury does not act strategically when setting
} 
petitive bids are then ranked in descending order, and the stop-out-price is determined in such a way that the aggregate competitive and non-competitive demand matches the exact quantity supplied. In order to adjust the quantity issued as precisely as possible, the Agence France Trésor reserves the right to scale-down bids at the lowest accepted price on a pro-rata basis. Auction results are announced within five minutes after the end of the auction, and the Banque de France completes the delivery-versus-payment orders with the auction winners within three business days. The security may then be traded to the general public on a secondary market. ${ }^{22}$

Although occasional bidders may participate, the French State's policy issuance essentially relies on a network of primary dealers (a.k.a. "Spécialistes en Valeurs du Trésor"). The role of these primary dealers is essentially to be active on the primary market, and to maintain a liquid secondary market. During the period studied, the primary dealers were composed of 19 institutions accounting for over $90 \%$ of the securities bought. The participation of the primary dealers to each French Treasury auction may vary notably between financial institutions. In particular, the Agence France Trésor identified five large financial institutions (Crédit Agricole, Deutsch Bank, BNP-Paribas, Morgan Stanley, and Société Générale) who were allocated during our sample period more than $50 \%$ of the securities issued.

To conclude this section, note that the presence of non-competitive bids, and the dominating participation of large financial institutions, suggest that a practitioner should account for supply uncertainty and asymmetries across bidders, in order to test whether these factors play a significant role in French Treasury auctions.

the exact quantity to be supplied. Conversations with French Treasury auctions specialists indicate that the final quantity decision appears to be an adjustment to exogenous short term shocks. Note also that, unlike Back and Zender (2001), the French government does not have an incentive to set endogenously the amount of security supplied, as the quantity available to competitive bidders in French Treasury auctions is random, in part due to the presence of non-competitive bids.

${ }^{22}$ The opening price of a security on the secondary market is often considered to be an imperfect measure of its actual value at the time of the auction. Indeed, there is a delay between the auction and the beginning of the trading period on the secondary market, actors on the secondary market may have heterogenous transaction costs, and less than half of the auctioned securities are in general traded on the secondary market (see Hortaçsu 2002a). Therefore, the true value of the security will be assumed to be an unobserved random variable whose distribution needs to be estimated. 


\subsection{Data}

The sample consists of 118 auctions (60 OAT and 58 BTAN) which took place at 64 different dates between May 1998 and December 2000. For each auction we observe i) the security pre-announced characteristics: the nominal yield, the maturity, whether the line is an OAT or a BTAN, and the upper and lower bounds of the bracket for the quantities served to the competitive and noncompetitive bidders; ii) the number of bidders in each group; ${ }^{23}$ iii) the quantity demanded for all prices by each individual bidder; and iv) the auction's outcomes: the stop-outprice, and the quantity served to each bidder. In addition, although our sample does not enable to identify any individual participant, it specifies whether a bidder belongs to the class of large or small financial institutions.

Summary statistics describing the auctions in our sample may be found in Table 1. Participation in French Treasury auctions appears to be dominated by smaller financial institutions (14.6 small banks versus 4.5 large banks). Although the number of bidders within groups may vary, the average number of participants (roughly 19) is rather stable across auctions and lines. As expected, the yield and maturity of the OAT are significantly larger than the BTAN's (respectively 5.5\% and 16 years for the OAT, versus $4.1 \%$ and nearly 3.5 years for the BTAN). The average volume of securities offered to competitive bidders (around 1,560 million Euros) may vary markedly from one auction to the next. This volatility may be only partially explained by non-competitive bids which represent on average slightly less than $3 \%$ of the total quantity supplied. Although in the minority, large banks received a larger share of the security (63.8\% on average). This result is consistent with the fact that, on average, large banks submit higher prices for the initial units demanded (101.193 versus 100.922 for small banks), and pay slightly more per unit awarded (101.185 versus 100.180). ${ }^{24}$ According with economic intuition, we also find a strong negative correlation between the average price paid and the quantity supplied by the Treasury. Interestingly, there is also a negative correlation between the quantity supplied, and the share awarded

\footnotetext{
${ }^{23}$ As previously mentioned, and following most of the structural literature on auctions, participation at a French Treasury auction is assumed to be exogenous and common knowledge. This assumption may be partially justified by the fact that a bidder's participation may be inferred from its activity on the primary market, as well as from pre-auction communications, which are prevalent according to French Treasury auctions specialists.

${ }^{24}$ To remain consistent with the French Treasury auctions practices, prices are expressed as a percentage of one euro. In other words, when we mention a price of 101.193 , it actually corresponds to a true price of 1.01193 euros.
} 
to large banks. In other words, small banks receive a greater percentage of the securities issued in large auctions. Note also that the stop-out-price is slightly, but not significantly smaller for BTAN (99.804) than for OAT (102.476). Finally, the revenue generated by the French Treasury during the period sampled (187 Billion Euros) may be almost equally divided between the auctions for BTAN and OAT, and it essentially originates from the contribution of large banks (roughly 63\%).

\section{Model Specification}

\subsection{Specification of the Constrained Strategies}

In practice, we define the family of constrained strategies $H^{(k)}$ for bidders in group $l=1,2$ as the two-dimensional polynomials of highest degree $k$ :

$\varphi_{i, l}^{(k)}\left(p, s_{i, l}, d_{l}\right)=\varphi_{i, l} I_{\left\{\varphi_{i, l}>0\right\}} \quad$ where $\varphi_{i, l}=d_{l}(0)-\sum_{j=1}^{k} \sum_{j^{\prime}=0}^{j} d_{l}(m) \cdot\left(\widetilde{s}_{i, l}\right)^{\left(j^{\prime}-j\right)} \cdot(\widetilde{p})^{j^{\prime}}$,

$m=j \cdot(j+1) / 2+j^{\prime}, \widetilde{p}=p-\left(\mu_{V}-4 \sigma_{V}\right), \widetilde{s}_{i, l}=s_{i, l}-\left(\mu_{V}-4 \sigma_{V}\right)$, and $\left(\mu_{V}, \sigma_{V}\right)$ are the mean and the standard deviation of the true value.

To be more specific, the French Treasury auction model will be estimated in a subsequent section with the constrained equilibrium $\operatorname{CSE}(2)$, derived within $H^{(2)}$, the set of constrained polynomial strategies of highest degree two: ${ }^{25}$

$$
\varphi_{i, l}=d_{l}(0)+d_{l}(1) \frac{1}{\widetilde{s}_{i, l}}+d_{l}(2) \widetilde{p}+d_{l}(3)\left(\frac{1}{\widetilde{s}_{i, l}}\right)^{2}+d_{l}(4) \frac{\widetilde{p}}{\widetilde{s}_{i, l}}+d_{l}(5) \widetilde{p}^{2}
$$

To evaluate the approximation quality of the $\operatorname{CSE}(2)$, the convergence criteria will be calculated with two alternative constrained equilibria, the CSE(1) and the $\operatorname{CSE}(3)$, derived in the constrained sets $H^{(1)}$ and $H^{(3)}$. As we shall see, the convergence criteria will be used to establish that the CSE(2) provides an excellent approximation, and that the use of a higher order polynomial is not necessary.

At this point four remarks are in order. First, in practice, the standardization of the prices and private signals $\left(p, s_{i, l}\right)$ into $\left(\widetilde{p}, \widetilde{s}_{i, l}\right)$ is necessary in order for the constrained bid function (7.2) to be non-linear. Indeed, the bid function would

\footnotetext{
${ }^{25}$ In fact, a distinct CSE(2) will be calculated for each auction in our sample, as the exogenous variables, such as the number of each type of bidders or the expected value of the security, vary from one auction to the next.
} 
otherwise be essentially linear for any parameter value $d_{l}$, since the variables $s_{i, l}$ and $p$ are defined in the French Treasury auctions over very small intervals roughly centered around 100. Second, although non-negativity constraints on bids are implicit in Wang and Zender (2002), numerical simulations of their model suggest that the probability of demanding negative equilibrium quantities is far from negligible for a wide range of parameter values. To avoid such undesirable outcomes at any step of our numerical algorithm, we explicitly impose non-negative quantities. Third, although we impose $d_{l}(t)>0$ for all $t$ (i.e. $\partial \varphi_{i, l}^{(k)}(\cdot) / \partial p<0$, and $\left.\partial \varphi_{i, l}^{(k)}(\cdot) / \partial s_{i, l}>0\right)$ to speed up computation, we verify that these constraints are non-binding at the equilibrium. As previously mentioned, the CSE is therefore strictly monotonic in prices and signals, which is an essential attribute to conduct a structural estimation. Fourth, to facilitate convergence at any step of the approximation algorithm, we only consider parameters for the constrained strategies such that i) the bidders' average profits are non negative, and ii) the stop-outprice systematically falls within the range of prices actually observed in the French Treasury auction for which the CSE is calculated. These constraints are shown to be non-binding at the equilibrium, but they considerably reduce computational time.

We now briefly motivate the choice of the family of constrained strategies in (7.1), over alternative candidates. First, when $k=1$ the CSE is consistent with uniform-price auction examples in Wilson (1979), and Fevrier et al. (2002). Second, the constrained strategies are bounded above when the private signals become large, which, in our experience, is a crucial property to derive efficiently the CSE numerically. Third, the CSE in this family of constrained strategies performed remarkably well to approximate accurately the equilibrium strategies derived analytically in specific examples of symmetric uniform-price auctions by Wilson (1979), Fevrier et al. (2002), and Wang and Zender (2002). Fourth, it outperformed several alternative specifications (e.g., other polynomial or piecewise linear functions with a similar number of parameters) both in terms of approximation quality, and computational time.

In addition, the family of constrained strategies defined in (7.1) has adequate properties to address in practice the questions of the CSE existence, uniqueness, and its relevance as an approximation. Indeed, if the (unconstrained) bid functions may be assumed to be continuous in $\left(p, s_{i, l}\right)$, and $\left(p, s_{i, l}\right)$ have compact supports bounded away from zero, then the generalization of the Weierstrass approximation theorem to functions of two variables guarantees that any (unconstrained) bid function may be approximated with arbitrary precision by a polynomial strategy 
of the form (7.1). In other words, the selected family of constrained sets is dense in the set of possible strategies, and any BNE of the game may be approximated by a sequence of CSEs.

Moreover, the existence of a CSE is established numerically in practice, by applying theorems and algorithms developed in interval analysis for the solution of nonlinear systems in the presence of computing rounding errors. In particular, if a nonlinear system of equations $F(x)=0, F: \mathbb{R}^{p} \rightarrow \mathbb{R}^{p}$, is Lipschitz continuous, then the application of the Krawczyk operator enables one to construct a box within which the existence and uniqueness of a solution may be formally verified numerically (see Neumaier 1990 and Kearfott 1996). Therefore, the existence and the uniqueness of a CSE in $H^{(k)}$ may be verified by applying such an algorithm to the set of first order conditions (5.1), in the neighborhood of an approximate solution derived numerically. ${ }^{26}$

The uniqueness result, however, is only local. In other words, as is often the case in games of incomplete information, we cannot formally prove the global uniqueness of a CSE. ${ }^{27}$ However, we were able to construct a box, centered on the approximated solution $d_{C S E}=\left(d_{1, C S E}, d_{2, C S E}\right)$, and with bounds $\left[0,2 d_{C S E}\right]$, within which the uniqueness of the CSE was formally established after applying the Krawczyk operator. ${ }^{28}$ In addition, the CSE was re-calculated $10^{6}$ time with an independent and random selection of starting values, and all solutions converged (in quadratic norm) toward the same CSE up to an $\varepsilon=10^{-12}$. This result therefore strongly suggests that the CSE calculated is indeed unique within a range of reasonable strategies.

Finally, the sequence of CSEs $\left\{\varphi_{C S E}^{(k)}\right\}_{k=1, \ldots, 5}$ in $H^{(1)}$ to $H^{(5)}$ was also calculated $10^{6}$ time with an independent and random selection of starting values. As further explained in section (9.2), each of the $10^{6}$ sequences converged toward the

\footnotetext{
${ }^{26}$ The GLOBSOL project (http://www.mscs.mu.edu/ globsol/) maintains a list of Fortran subroutines based on interval arithmetic to solve optimization problems and non-linear system of equations.

${ }^{27}$ To facilitate the presentation, the discussion that follows concentrates on the uniqueness of a CSE and a BNE in a specific model. Recall however that the characteristics of the model, and therefore the CSE calculated, are distinct for each auction in our sample, as the exogenous variables differ. In other words, the calculations described below to address the question of uniqueness, were in fact (successfully) repeated for each auction in our sample.

${ }^{28}$ The fact that the uniqueness could not be established for some CSEs in wider boxes does not necessarily implies that the solution is not unique, but rather that the uniqueness test was inconclusive.
} 
same BNE up to an $\varepsilon=10^{-11} .^{29}$ This result therefore strongly suggests that, beside the equilibrium we approximated, there is no other well behaved BNE. However, if the game happened to possess additional equilibria, then the previous calculations show that the BNE approximated may at least be considered as a sensible, strong focal point equilibrium. Under these circumstances, it may be reasonably assumed, when we estimate the structural model, that agents have coordinated on the BNE we approximated.

\subsection{Specification of the Econometric Model}

Before we turn to the specification of the structural model, we must estimate the distribution of $Q_{t}$, the quantity actually supplied at auction $t$ to competitive bidders. We assume that $Q_{t}$ is exogenously determined by the following relationship

$$
\begin{aligned}
Q_{t}= & \alpha_{0}+\alpha_{1} \text { MeanBracket }_{t}+\alpha_{2} \text { SpreadBracket }_{t}+ \\
& \alpha_{3} \text { Maturity }_{t}+\alpha_{4} \text { Yield }_{t}+\alpha_{5} \text { Type }_{t}+v_{t}
\end{aligned}
$$

where MeanBracket $t=\left(\underline{Q}_{t}+\bar{Q}_{t}\right) / 2$, SpreadBracket S $_{t}=\left(\bar{Q}_{t}-\underline{Q}_{t}\right) / 2, \bar{Q}_{t}$ and $\underline{Q}_{t}$ are the upper and lower bounds of the quantity bracket announced by the French Treasury before auction $t$, and $v_{t}$ is an identically and independently normally distributed error term with mean zero and variance $\sigma_{v}^{2} \cdot{ }^{30}$ The results of the regression presented in Table 2 indicate that the quantity supplied, cannot be explained solely by the bracket announced by the auctioneer. Indeed, the characteristics of the security for sale (i.e., the maturity, yield and type) appear to have a non-negligible impact on the quantity offered to competitive bidders. Since the parameter associated with the spread of the quantity bracket is not significantly different from zero, we re-estimated the model without this variable (see Table 2). The estimated parameters now fully characterize the probability distribution of the quantity supplied to competitive bidders. In the remainder, it is assumed that bidders know this distribution of $Q_{t}$ when they calculate their optimal strategy.

\footnotetext{
${ }^{29}$ This result contrasts sharply with similar calculations we originally conducted under the assumption that the quantity supplied to competitive bidders is common knowledge. Indeed, in this case the sequences of CSEs would either not converged, or they would converged toward different BNEs. The introduction of random supply is therefore not only empirically relevant, but, as suggested by (e.g.) Wang and Zender (2002), it also appears to eliminate multiple equilibria.

${ }^{30}$ On rare occasions, the French Treasury is known to supply a quantity slightly larger than $\bar{Q}_{t}$. Consequently, we leave the distribution of $Q$ unbounded.
} 
To complete the econometric specification, we assume that $V_{t}$, the true value of the security at auction $t$, is normally distributed with mean $\mu_{V_{t}}=\delta_{0}+\delta_{1} Y$ ield $t_{t}+$ $\delta_{2}$ Maturity $_{t}+\delta_{3}$ Type $_{t}$, and variance $\sigma_{V}^{2}$. The conditional distribution of $s_{i, l}^{t}$, the private signal at auction $t$ of bidder $i$ in group $l(l=1,2)$, is assumed to be a normal with mean $V_{t}$ and variance $\sigma_{l}^{2} \cdot{ }^{31}$ Note that the assumption that the variables $Q, V$, and $s_{i, l}$ are normally distributed not only is standard in econometrics, but it is also supported by the graphs of the variables respective (estimated) values. Moreover, unlike Fevrier et al. (2002) and Castellanos and Oviedo (2002) who adopted a exponential distribution, the private signals are symmetrically distributed around the true value, which appears to be a natural assumption.

\section{Estimation of the Structural Model}

The objective of the inference method presented here, is to estimate the unknown structural parameter $\theta=\left(\beta, \sigma_{1}, \sigma_{2}, \lambda_{1}, \lambda_{2}\right)$, where $\beta=\left(\delta_{0}, \delta_{1}, \delta_{2}, \delta_{3}, \sigma_{V}\right)$ characterizes the distribution of the true value of the security. To do so, we apply the method of simulated moments (MSM) as originally introduced by McFadden (1989), and Pakes and Pollard (1989).

Consider the identically and independently distributed sequence of observations $\left(q_{i, l}^{j, t}, Z_{l}^{j, t}\right)$, where $q_{i, l}^{j, t}$ is the endogenous variable representing the quantity demanded at price $p_{j}\left(j=1, \ldots, J_{t}\right)$ by bidder $i\left(i=1, \ldots, N_{l, t}\right)$ in group $l(l=1,2)$ at auction $t(t=1, \ldots, T)$, and $Z_{l}^{j, t}=\left(1, p_{j}, z_{l}^{t}\right)$ is a $11 \times 1$ vector of exogenous variables, in which $z_{l}^{t}$ accounts for some of the characteristics of group $l$ and of auction $t .{ }^{32}$

The observed bid $q_{i, l}^{j, t}$ is assumed to be determined, up to an error term, by

\footnotetext{
${ }^{31}$ To guarantee that a sequence of CSE approximates an equilibrium we have previously assumed that the support of the private signals is compact. To remain consistent with this assumption, we can truncate the distribution of the private types far in the tail. Therefore, when approximating a CSE, we only consider signals within 5 standard deviations around their mean. This type of truncation was adopted by (e.g.) AFR (2001) and Eklöf (2003), and it is inconsequential for the econometric estimation.

${ }^{32}$ In practice, we consider $z_{l}^{t}=\left(\text { Y ield }_{t}, \text { Maturity }_{t}, \text { Type }_{t}, N_{1, t}, N_{2, t}, \underline{Q}_{t}, \bar{Q}_{t}, Q N C B_{t}, \text { Large }_{l}\right)^{\prime}$ where Large ${ }_{l}$ is a dummy variable equal to 1 when $l=1$ (i.e. when the bank belongs to the group of large financial institutions), and $Q N C B_{t}$ is the percentage of the total quantity supplied demanded by non-competitive bidders at auction $t$.
} 
the $\operatorname{CSE}(k)$ bid function derived at auction $t$ :

$$
q_{i, l}^{j, t}=\varphi_{l, C S E}^{(k)}\left(p_{j}, s_{i, l}^{t}\right)+\omega_{i, l}^{j, t},
$$

where $s_{i, l}^{t}$ is the private signal of bidder $i$ in group $l$ at auction $t$, and $\omega_{i, l}^{j, t}$ is an identically and independently distributed error term satisfying $E_{\theta}\left[\omega_{i, l}^{j, t} \mid Z_{l}^{j, t}\right]=0 .{ }^{33}$ The error term may be interpreted as a combination of three factors: players mistakes when deriving or playing their equilibrium strategies, measurement errors due to the fact that bidding is only permitted in practice on a grid of prices, and approximation errors due to the use of a CSE.

Let us denote $h\left(Z_{l}^{j, t}, \theta\right)=E_{\theta}\left[\varphi_{l, C S E}^{(k)}\left(p_{j}, s_{i, l}^{t}\right) \mid Z_{l}^{j, t}\right]$ the expected quantity demanded at price $p_{j}$ by a bidder in group $l$ during auction $t$, conditionally on the vector of exogenous variables $Z_{l}^{j, t}$. We can then generate a set of moment conditions of the form:

$$
E_{\theta}\left[Z_{l}^{j, t}\left(q_{i, l}^{j, t}-h\left(Z_{l}^{j, t}, \theta\right)\right)\right]=0 .
$$

The generalized method of moments estimator is based on the empirical counterpart of the previous orthogonality conditions:

$$
\widehat{\theta}_{G M M}=\underset{\theta \in \Theta}{\operatorname{Arg} \min }\left[A^{\prime} \Omega A\right] \text { where } A=\sum_{t, j, l, i} Z_{l}^{j, t}\left(q_{i, l}^{j, t}-h\left(Z_{l}^{j, t}, \theta\right)\right),
$$

and $\Omega$ is a $11 \times 11$ symmetric, positive definite matrix that may be chosen in order to minimize the variance of the estimator. Note that this model is over-identified, as there are eleven moment conditions to estimate a parameter of dimension nine.

In the present context, the generalized method of moments estimator is not directly implementable since the expectations $h\left(Z_{l}^{j, t}, \theta\right)$ cannot be derived analytically. Following the MSM technique, as reviewed by Carasco and Florens (2002), we propose replacing $h\left(Z_{l}^{j, t}, \theta\right)$ by a Monte Carlo approximation $\bar{h}_{M C}\left(Z_{l}^{j, t}, \theta\right)=$ $\frac{1}{M C} \sum_{m=1}^{M C} \varphi_{l, C S E}^{(k)}\left(p_{j}, \widehat{s}_{i, l}^{t}(m)\right)$, where $M C$ is the size of the Monte Carlo simulation, and $\widetilde{s}_{i, l}^{t}(m)$ is a simulated private signal randomly generated from the distribution $f\left(. \mid \theta, Z_{l}^{j, t}\right)$.

\footnotetext{
${ }^{33}$ Note that the addition of an error term to the equilibrium bid function is necessary in practice to reconcile for each auction in our sample, a bidder's unique private signal, with the different quantities she demanded at each of the possible prices. Otherwise, the inversion of an equilibrium bid function at each of the observed bids $q_{i, l}^{j, t}$ submitted at prices $p_{j}\left(j=1, \ldots, J_{t}\right)$ would not necessarily result in the unique private signal $s_{i, l}^{t}$.
} 
Gourieroux and Monfort (1995) show that the MSM estimator is strongly consistent and asymptotically normal when $M C$ is fixed. In addition, they show that the optimal matrix $\Omega^{*}$, which minimizes the variance of the estimator, is given by

$$
\begin{aligned}
\left(\Omega^{*}\right)^{-1}= & \operatorname{Var}_{\theta}\left[Z_{l}^{j, t}\left(q_{i, l}^{j, t}-h\left(Z_{l}^{j, t}, \theta\right)\right)\right]+ \\
& \frac{1}{M C} \operatorname{Var}_{\theta}\left[Z_{l}^{j, t}\left(\varphi_{l, C S E}^{(k)}\left(p_{j}, \widehat{s}_{i, l}^{t}(m)\right)-h\left(Z_{l}^{j, t}, \theta\right)\right)\right] .
\end{aligned}
$$

However, $\Omega^{*}$ cannot be derived directly as it depends on the unknown distribution. Following Gourieroux and Monfort (1995), $\Omega^{*}$ is replaced by a sequence of consistent estimators:

$$
\begin{aligned}
\left(\widehat{\Omega}_{r+1}^{*}\right)^{-1}= & \frac{1}{M} \sum_{t, l, j, i} Z_{l}^{j, t} B_{1}\left(q_{i, l}^{j, t}, Z_{l}^{j, t}, \widehat{\theta}_{r}\right) B_{1}\left(q_{i, l}^{j, t}, Z_{l}^{j, t}, \widehat{\theta}_{r}\right)^{\prime}\left(Z_{l}^{j, t}\right)^{\prime}+ \\
& \frac{1}{M \cdot M C} \sum_{t, l, j, i} Z_{l}^{j, t} B_{2}\left(q_{i, l}^{j, t}, Z_{l}^{j, t}, \widehat{\theta}_{r}\right) B_{2}\left(q_{i, l}^{j, t}, Z_{l}^{j, t}, \widehat{\theta}_{r}\right)^{\prime}\left(Z_{l}^{j, t}\right)^{\prime}, \\
\text { where } \quad & B_{1}\left(q_{i, l}^{j, t}, Z_{l}^{j, t}, \widehat{\theta}_{r}\right)=q_{i, l}^{j, t}-\frac{1}{M C_{2}} \sum_{m=1}^{M C_{2}} \varphi_{l, C S E}^{(k)}\left(p_{j}, \check{s}_{i, l}^{t}(m)\right), \\
& B_{2}\left(q_{i, l}^{j, t}, Z_{l}^{j, t}, \widehat{\theta}_{r}\right)=\varphi_{l, C S E}^{(k)}\left(p_{j}, \widehat{s}_{i, l}^{t}(1)\right)-\frac{1}{M C_{2}} \sum_{m=1}^{M C_{2}} \varphi_{l, C S E}^{(k)}\left(p_{j}, \check{s}_{i, l}^{t}(m)\right),
\end{aligned}
$$

$M$ is the sample size, $\widetilde{s}_{i, l}^{t}(1)$ is the first element of the sequence $\left\{\widetilde{s}_{i, l}^{t}(m)\right\}_{m=1, \ldots, M C}$, $\left\{\check{s}_{i, l}^{t}(m)\right\}_{m=1, \ldots, M C_{2}}$ is a new sequence of $M C_{2}$ simulated signals randomly and independently generated from the distribution $f\left(. \mid \widehat{\theta}_{r}, Z_{l}^{j, t}\right) ; \widehat{\theta}_{r}(\forall r \geq 1)$ is the MSM estimator of $\theta$ calculated with the weighting matrix $\widehat{\Omega}_{r-1}^{*}$, and $\widehat{\Omega}_{0}^{*}$ is the identity matrix. In practice we set $r=2, M C=10^{6}$ and $M C_{2}=10^{8}$.

Note that unlike Fevrier et al. (2002), we take full advantage of each observation (i.e., each price-quantity pair observed for each bidder), rather than only the quantities submitted at the stop-out-price by the winning bidders. ${ }^{34}$ More precisely, not only do we take into considerations every prices at which a bid is submitted (i.e., the points at which an observed (step) demand function strictly

\footnotetext{
${ }^{34}$ The sample used in our estimation method consists of 40,496 observations, while it would have been reduced to 1,158 observations had we taken into account only the quantities observed at the stop-out-price.
} 
decreases), but we also account in the estimation process for all possible prices in our sample, for which a bidder did not require an additional share (i.e., the prices at which a demand function remains flat). This latter set of data points should not be ignored, as it also contains information about the bidders' strategy. Indeed, such observations indicate that at a given price the bidder did not wish to modify the quantity she demanded.

As is often the case with structural models, the global identification of the model is far from trivial to establish. We derive in appendix a numerical procedure that allows us to confirm that our model is locally identified around the parameters estimated in the subsequent section. As suggested by Athey and Haile (2002), as well as Campo, Guerre, Perrigne and Vuong (2002), this identification result may be explained intuitively by the fact that we exploit the observed heterogeneity between the auctions in our sample. For instance, the identification of the risk aversion parameters may be attributed to the variation in the number of each type of bidders, as these variables enter the expected utility functions, but not the distributions of the values or signals. Note also that the number of exogenous variables necessary to obtain identification, prevents us from estimating the model semi- or non-parametrically (as in Guerre et al. 2000), as we would then face the "curse of dimensionality" problem. Our model, however, relies on similar parametric assumptions as (e.g.) Paarsch (1992), and Donald and Paarsch (1993, 1996) in the estimation of single unit auctions, as well as Fevrier et al. (2002) in the estimation of a Treasury auction model.

\section{Estimation Results}

\subsection{Estimated Structural Parameters}

The value of the estimated parameters are presented in Table 3. In order to draw some comparisons with the auctions outcomes observed in our sample, we use the estimated parameters to conduct $10^{6}$ Monte Carlo simulations for each auction in our sample. The results of these simulations are summarized in Table 4.

Let us concentrate first on the parameters $\left(\delta_{k}, \sigma_{V}\right)$ characterizing the mean and standard deviation of the value of a security. As expected, $\delta_{1}$ is significantly greater than 0 , reflecting the fact that the value of a security increases (on average) with its yield. Table 3, also indicates that long term securities are on average slightly less valuable to bidders $\left(\delta_{2}<0\right)$. Note, however, that after controlling for the maturity, and according with opinions expressed by French Treasury spe- 
cialists, we do not find any evidence indicating that the value of the two types of short and long term securities differs significantly (i.e., $\delta_{3}$ is insignificant). Table 3 indicates that the values of the estimated parameters vary slightly when we impose $\delta_{3}=0$. In the remainder, we only rely on this new set of significant structural parameters when conducting Monte Carlo simulations. The average value of a security in our sample is evaluated at 101.772, 0.610 above the average stopout-price (see Table 4). The estimated difference between the true value and the stop-out-price is significantly smaller than the one found by Fevrier et al. (2002) (i.e. 1.85). Recall, however, that Fevrier et al. studied a different period (1995), and that the sample they use is substantially smaller. Finally, note that the true value of a security conditional on the exogenous variables is somewhat variable, since the standard deviation $\sigma_{V}$ is estimated at 0.632 (Table 3 ). ${ }^{35}$

We now turn to the estimation of the standard deviations of private signals. Table 3 indicates that small banks receive noisier signals (i.e., $\sigma_{2}>\sigma_{1}$ ). To test for informational symmetry (i.e., $\sigma_{2}=\sigma_{1}$ ) we adopt the extension to the general method of moment framework of the Wald test (see e.g., Newey and West 1987). The Wald statistic is 113.291 , which corresponds to a $P$-value of $2.665 \mathrm{E}-4$. In other words, we can reject the hypothesis that participants to the French Treasury auctions have access to the same source of information regarding the value of the security for sale. Nothing indicates, however, whether the informational advantage of large banks is due to better market research, inferences from the flow of preauction orders submitted to large banks by their own customers (as suggested by Bikchandani and Huang 1993), or informal pre-auction communications (as suggested by Nandi 1997 and Hortaçsu 2002).

Finally, Table 3 also indicates that the CARA parameter of small banks is more than one hundred time larger. ${ }^{36}$ The CARA specification however, does not include risk neutrality as a special case. Therefore, we must adopt a nonnested approach to test whether bidders are risk neutral. Following Singleton (1985), we create a more general structural model nesting as special cases both Treasury auction models under the CARA (model M1) and risk neutrality (model

\footnotetext{
${ }^{35}$ The standard deviation of the true value and the standard deviation of the privates signals are not explicitly given in Fevrier et al. (2002). Therefore, we have not been able to compare our estimates with theirs.

${ }^{36}$ The estimated absolute risk aversion parameters may appear rather low, if not compared to the profits of the bidders. Indeed, the relative risk aversion levels range between 0.02 and 0.9 when calculated with the profits only. These figures, although still low since they do not include the actual wealth of the participants, appear however more reasonable.
} 
M2) assumptions. ${ }^{37}$ The implementation of the test however, only requires to reestimate the model under the risk neutrality assumption. We find that the statistic associated with the test of M1 against M2 (respectively M2 against M1) is 1.789 (9.180), which corresponds to a $P$-value of 0.181 (2.446E-3). Therefore, we are lead to conclude in favor of the presence of risk aversion. We also performed a test similar to the one previously conducted to verify informational symmetry, in order to test for the equality of the risk aversion parameters between the two groups of bidders (i.e., $\lambda_{2}=\lambda_{1}$ ). The test statistic is 24.406, which corresponds to a $P$-value of $7.803 \mathrm{E}-7$. In other words, we can reject the hypothesis that both types of bidders have comparable level of risk aversion. These results, however, are not sufficient to compare bidders in terms of relative risk aversion. Indeed, small and large banks typically have different levels of wealth. Individual data on the participants' wealth were not accessible to us. However, the simulations conducted in Table 4 indicate that the average profits per auction of a small and a large bank are respectively around 0.14 and 1.27 million Euros. Therefore, if it may be assumed, as a simplification, that a bank's wealth is roughly proportional to its profits in the French Treasury auctions, then small banks' relative level of risk aversion is 13.3 time larger. In other words, the estimation of the structural parameters confirms that large financial institutions possess better information, and are willing to take more risks.

It is interesting to note that the informational and risk aversion asymmetries have unequal consequences on the auction outcomes in general, and the Treasury revenues in particular. Indeed, if small banks were to receive private signals generated from the same distribution as their larger counterparts, then, all things being equal otherwise, this would raise the Treasury's revenue by $12 \%$, while the average profits of a large (small) bank would decrease (increase) by $21 \%(8 \%) .{ }^{38}$ Alternatively, if small banks had the same CARA parameter as large banks (but still receive noisier information), then the Treasury's revenue would barely change $(+3 \%)$, while the small (large) banks' profits would only increase (decrease) by $3 \%(7 \%)$. In other words, benefits to the French Treasury would be non-negligible if participants had access to similar sources of information. This result may be of importance, since, unlike risk aversion, policy makers may be able to curb

\footnotetext{
${ }^{37}$ The risk neutral model is derived and approximated along the same lines as the CARA model, except that bidders maximize their expected profits in equation (3.1), instead of their expected utility in equation (3.2).

${ }^{38}$ The unequal effect of a reduction of the informational asymmetry on small and large banks may be explained by the fact that the security is now allocated to a larger number of small banks.
} 
down the informational asymmetry. Indeed, it may be possible, for instance, to regulate pre-auction communications, which is often believed to be one of the principal sources of informational asymmetry.

Table 4 also indicates, as previously mentioned, that large and small banks expected profits are roughly 1.27 and 0.14 million Euros per auction. ${ }^{39}$ These figures, however, do not include any research or administrative costs typically incurred while participating in Treasury auctions. Finally, it is important to note that large banks appear to be facing a non-negligible winner's curse problem. ${ }^{40}$ Indeed, the share of securities awarded to a large bank is bought at an average price exceeding the true value of the security $8.5 \%$ of the time. In sharp contrast, small banks, which behave more prudently, are affected by the winner's curse for only $1 \%$ of the shares they received.

Finally, the simulations in Table 4 suggest that the estimated model is sensible, as it replicates fairly well the outcomes observed in our sample of French Treasury auctions. For instance, the simulated stop-out-price, the average price paid by unit, the highest price at which a positive quantity was demanded, the repartition of the security between each type of banks, and the revenue generated by the Treasury, are very similar in Tables 1 and 4 . In addition, the negative correlations observed in the sample between the quantity of security issued on one hand, and the average price paid or the share allocated to large banks on the other hand, are also identified with our simulated model.

\subsection{Approximated Equilibrium}

Although apparently sensible, the quality of the previous results is crucially contingent on the fact that the CSEs considered for the estimation of the structural model are accurate approximations of the equilibria in each Treasury auction in our sample. Therefore, we now turn to the evaluation of the $\operatorname{CSE}(2)$, its theoretical properties, and the convergence criteria. The parameters of a CSE(2), derived for both types of players and specific values of the exogenous variables, are reported in Table 5. The corresponding bid functions are illustrated by the solid lines in Graph 1, and the influence of the private signals on the bids submitted

\footnotetext{
${ }^{39}$ This result is consistent with Umlauf (1993) who found that large bidders earn significantly larger profits in Mexican Treasury bill auctions.

${ }^{40}$ The "winner's curse" is said to occur when a winning bidder realizes that the price he paid exceeds the value of the object he was awarded. See Capen, Clapp and Campbell (1971), as well as Kagel (1995) for empirical and experimental evidence of the winner's curse in single-unit auctions.
} 
may be appreciated in Graph 2. Finally, the convergence criteria may be found in Table $6 .{ }^{41}$

Graph 1 confirms that small banks behave more prudently. Indeed, the demand functions submitted by small banks are not only shifted downward, but they are also slightly flatter than the demand functions of their larger counterparts. In other words, small banks systematically ask fewer shares at any possible price, and they are not willing to pay as much to obtain an additional unit of the security. Monte Carlo simulations suggest that the differences between the bid functions of each group of players cannot be imputed solely to either the information or the risk-aversion asymmetry. In fact, the shape of the strategies appears to be almost equally influenced by the two sources of asymmetry.

Graph 2 indicates that private signals have a significant impact on the bid functions. ${ }^{42}$ For instance, in comparison with the average private signal of 101.772, private signals of 101.807 and 101.912 (the mean of the private signals plus 0.5 and 2 standard deviations), yield a large bank a share approximately $10 \%$ and $30 \%$ larger on average.

Although the demand functions in Graph 1 appear essentially linear, the equilibrium parameters in Table 5 indicate that the CSE is a non-linear function of both prices and private signals (i.e., $d(4)$ and $d(5)$ are different than 0 ). This observation is confirmed by the convergence criterion $C_{3}$ in Table 6 , which indicates that any player has a strong incentive (especially in absolute terms given the large amounts of money involved in Treasury auctions) to shift to an unconstrained strategy when its opponents play the linear constrained equilibrium $\operatorname{CSE}(1){ }^{43}$

The convergence criteria in Table 6 indicate that the $\operatorname{CSE}(2)$ is an excellent approximation of the equilibrium since i) it almost perfectly matches its unconstrained best-response (criterion $C_{1}$ ); and ii) it is a BNE in a game with an almost

\footnotetext{
${ }^{41}$ The convergence criteria reported in Table 6 are aggregated across both types of players. These criteria, however, do not differ significantly when calculated separately with small or large banks.

${ }^{42}$ The relative impact of private signals on the demand function submitted by both types of players is roughly similar. Therefore, we only report in Graph 2 the effect of private signals on the strategy of large banks.

${ }^{43}$ In fact, if a small (respectively, large) bank best-responds with a quadratic constrained strategy belonging to $H^{(2)}$ to its opponents, who all use the linear constrained equilibrium CSE(1), then this player would increase its profits by $5.70 \%$ (respectively $5.93 \%$ ) on average. In other words, bidders have a strong incentive in this situation to shift from a linear, to a non-linear strategy belonging to $H^{(2)}$.
} 
identical distribution (criterion $C_{4}$ ). Criterion $C_{4}$ also confirms that the specification error due to the use of the approximated equilibrium CSE(2) instead of the actual BNE did not significantly affect the estimation of the structural parameters of the model in Table 3. Note also that a higher order polynomial, would considerably increase computational time, but it would not improve significantly the quality of the approximation, as indicated by the convergence criteria associated with the alternative $\operatorname{CSE}(3)$. This result is consistent with our experiences with other auctions models. Indeed, although analytically complex and often untractable, BNE in auction models are typically well behaved monotonic functions that may be approximated accurately by a low order polynomial. In other words, the CSE(2) adopted for the estimation of the structural model, provides a parsimonious, yet sensible approximation.

An alternative approach to assess the pertinence of the approximated equilibrium is to verify whether its properties are consistent with theoretical results established analytically in the symmetric case. ${ }^{44}$ In accordance with Ausubel and Cramton (2002), and Wang and Zender (2002), we find that in our asymmetric model i) both types of bidders shade their bids relative to their marginal valuation of the security; ii) the intensity of a player's bid shading increases with his risk aversion and private signal; iii) equilibrium bid schedules, as well as the seller's expected revenue, increase with the number of participants (of any group), and the expected value of the security, but they decrease with the bidder's level of risk aversion and the variance of the true value; and iv) the probability of the winner's curse is not zero, it increases with the variance of the true value and the number of participants, while it decreases with the bidder's parameter of risk aversion. In other words, the CSE(2) also appears to be sensible in the sense that it shares its main properties with known symmetric equilibria.

\section{Discriminatory Versus Uniform-Price Formats}

Using the structural parameters estimated in the previous section (i.e. third column in Table 3), we now approximate with a $\operatorname{CSE}(2)$ what would have been the bidders equilibrium behavior, had the French Treasury conducted the auctions in our sample with a uniform pricing rule. The parameters of a $\operatorname{CSE}(2)$ in the uniform-price auctions are presented in Table 7, and the corresponding equilibrium

\footnotetext{
${ }^{44}$ Failure to be consistent with symmetric models does not necessarily invalidate our asymmetric model, since properties from symmetric models do not necessarily extend to asymmetric models.
} 
bid schedule are plotted in Graph 1 (dotted line). Then, using these approximated equilibria, a Monte Carlo simulation has been conducted to compare the auctions outcomes in the uniform-price format (Table 9), with those previously found in the discriminatory format (Table 4$).{ }^{45}$

Note that when comparing the two pricing rules, we implicitly assume that the variables considered exogenous, such as the quantity available to competitive bidders or the number of competitive bidders, remain unaffected after switching to a different auction format. This assumption may be questioned since participation and/or non-competitive bids could be expected to differ between a discriminatory and uniform-price auction. However, to the best of our knowledge, the different empirical analysis conducted after natural experiments did not find any conclusive evidence suggesting that a pricing rule significantly affects the variables that have been assumed exogenous in the present paper. This result may be partially explained by the fact that the number of participants, and the number of banks allowed to submit non-competitive bids, are typically inelastic in the short term. Indeed, bidders must first pre-qualify by receiving an accreditation from the government.

Before describing the equilibrium behavior in the uniform-price auction, let us point out that the approximated equilibrium bid function $\operatorname{CSE}(2)$ is once again remarkably precise, as indicated by the convergence criteria in Table 8. In addition, the approximated equilibrium appears sensible, as its properties are consistent with Ausubel and Cramton (2002), and with a comparable symmetric example in Wang and Zender (2002). For instance, we find that i) both types of bidders shade their bids; ii) the intensity of bid shading falls compared to the discriminatory case; iii) bid shading diminishes with added competition (from any group), iv) reducing the severity of the winner's curse through information revelation about the true value and/or the amount of non-competitive bidding, increases the seller's expected revenue; v) the seller's expected revenue increases with the average value of a security, and the number of competitive bidders (from any group), while it decreases with risk aversion, and the variance of the true value; vi) finally, the demand of a bidder is strictly positive when the signal and the price are simultaneously equal to the average true value of the security (i.e., $\varphi_{l, C S E}^{(2)}\left(p_{j}, s_{i, l}\right)>0$

\footnotetext{
${ }^{45}$ The Monte Carlo simulations rely on the common random number technique. In other words, Tables 4 and 9 are constructed with the same exogenous variables and pseudo-random private signals, and, therefore, they can be directly compared. In addition, the standard deviations in Tables 4 and 9 are calculated across simulations, and across auctions in our sample. In other words, these standard deviations should not be confused for a measure of the accuracy of an estimate, as often presented along the results of a regression.
} 
when $s_{i, l}=p_{j}=\mu_{V}$ ).

To understand the difference between equilibrium behavior under each auction format, it is important to remember that a fundamental characteristic of uniformprice auctions is that bidders do not pay their bid for each unit they receive. Instead, a winning bidder pays a single price, the stop-out-price, for every units she is allocated. As a result, bidders are inclined to announce higher prices than at discriminatory auctions, for the first units demanded. Indeed, strategic bidders realize that the stop-out-price they will have to pay will be lower than the price they announced for these initial shares. This intuition is confirmed in Table 9 and Graph 1. Indeed, the highest prices at which bidders demand a strictly positive share is lower for both types of bidders under the discriminatory format (101.204 and 100.945 for large and small banks, versus 101.449 and 101.325 in uniformprice auctions). To compensate for the high prices submitted for the initial units, we can also see in Graph 1 that the demand functions are flatter in the uniformprice auction (dotted lines), in order to keep the stop-out-price as low as possible. As expected, however, the stop-out-price is always higher in the uniform-price auction. Interestingly, the average stop-out-price in the uniform-price auction lays between the average price paid by large and small winning banks in the discriminatory format.

Note also that a shift from the discriminatory to the uniform-price format leads small banks to take relatively more risk compared to their larger counterparts. Indeed, Graph 1 shows that the demand function of small banks shifts upward, and is only marginally flatter in the uniform-price format. In other words, knowing that they will not have to pay the price they announced, small banks are willing to buy larger amounts of the security at any relevant price. The bid function of large banks, on the other hand, rotates and becomes significantly flatter. As a result, large banks are willing to pay more than in a discriminatory auction for small quantities, but they do not wish to spend as much to obtain a large share of the security.

According to our model, these strategy adjustments on the part of both types of bidders when switching to the uniform-price format imply: i) the percentage of the security awarded to small banks is significantly higher (55\% versus $37 \%$ in the discriminatory format); ii) a larger number of small banks is likely to be awarded a share of the security; and iii) the increase in the share allocated to small banks is relatively higher at auctions with low quantities issued by the Treasury. In other words, the negative correlation between the quantity supplied and the share allocated to large banks is reduced under the uniform-price format. These 
theoretical predictions are consistent with the empirical observations in Malvey and Archibald (1998) who report that the average share awarded to the top five and top ten dealers declined by about $10 \%$ to $17 \%$ after the US Treasury shifted to the uniform pricing rule.

The combined effect of the uniform-price auction on the stop-out-price and the allocation process, has in turn surprising consequences in terms of the banks' utility, and the Treasury's revenue. Indeed, Table 9, indicates that the expected utilities of both types of banks, and the revenue of the Treasury would simultaneously increase under the uniform-price format. This result may be explained by the combination of two factors. First, a comparison of Tables 4 and 9 indicates that the uniform-price format significantly reduces the variance of the profits for both types of bidders. ${ }^{46}$ This reduction in profits' volatility is such that the expected utility of small banks, who are relatively more risk averse, increases on average under the uniform pricing rule, even though their expected profits are actually $2.8 \%$ lower on average. The expected utility of large banks increases as well in uniform-price auctions, since not only their profits volatility diminishes, but also their expected profits rise following a reduction of the winner's curse problem (from $8.5 \%$ to $0.7 \%$ of the shares allocated). ${ }^{47}$ Second, as previously mentioned, a comparison of Tables 4 and 9 indicates that the average stop-out-price in the uniform-price auction (101.184) is larger than the average price paid by small banks (101.179), but only slightly smaller than the average price paid by large banks (101.186) under the discriminatory format. As a result, the average price paid by a bank (regardless of type) for a unit of the security is larger under the uniform-price format. This implies that the revenue raised by the French Treasury during our sample period would have been higher under the uniform price format. The uniform-price format therefore appears do dominate the discriminatory format in French Treasury auctions, both from the Treasury's perspective, but also from a social welfare perspective.

Although the Treasury's revenue increase is modest in relative terms (4.8\%), it is quite consequent in absolute terms. Indeed, we estimate that the French Treasury would have accumulated an additional 9 billion Euros during our sample

\footnotetext{
${ }^{46}$ This reduction may be essentially explained by a decline, under the uniform-price format, of the negative correlation between the quantity supplied by the Treasury on one hand, and the average price paid and the share allocated to large banks on the other hand. In other words, under the uniform pricing rule, banks receive more uniform shares and pay more uniform prices independently of the quantity of security issued.

${ }^{47}$ Unlike Castellanos and Oviedo (2002), the reduction of the winner's curse alone cannot explain why the uniform price auction generates higher revenues for the French Treasury.
} 
period, had it used a uniform-price auction. Our simulations, however, suggest a potential drawback associated with the uniform pricing rule. Indeed, the standard deviations of the per-auction Treasury revenues in Tables 4 and 9 indicate that the revenue raised by the Treasury is significantly more variable from one auction to the next under the uniform-price format. ${ }^{48}$ In other words, although the Treasury revenue is higher under the uniform-price format, the precise amount of money an auction will generate becomes less predictable. Under these circumstances, it may be more difficult for the French government to use the uniform-price Treasury auction as an efficient short-term tool to manage its public debt. ${ }^{49}$

Our results are therefore consistent with the reduced-form analysis conducted by Malvey and Archibald (1998) after the US Treasury decided to experience with the uniform pricing rule. Indeed, the authors found: i) the revenue of the Treasury increased slightly in relative terms, but not significantly; and ii) the revenue raised by the US Treasury became more variable from one auction to the next. Moreover, our simulations illustrate why most reduced-form analyses conducted after natural experiments have failed to produce an unambiguous ranking of auction mechanisms. Indeed, we find that the uniform pricing rule would only result in a relatively marginal increase in revenue, while simultaneously generating more variable outcomes. In such a noisy environment, it would be extremely difficult to identify such a small revenue difference with a reduced-form analysis. The task may be rendered even more difficult with field data, as they might be polluted by other sources of noise generated by time effects, variations in the values of the exogenous variables, or players adjusting to the new environment.

As mentioned in the introduction, our results are context specific, and they may not extend directly beyond the French Treasury experience. Indeed, Monte Carlo simulations suggest that alternative values of the structural parameters may yield different conclusions. In particular, like Fevrier et al. (2002), we find that the discriminatory format would generate higher revenues for the Treasury than the uniform-price auction, if bidders are risk neutral and small banks receive private signals drawn from the same distribution as their larger counterparts. Our results, however, appear to be robust in the context of the French Treasury auctions, since

\footnotetext{
${ }^{48}$ This increase in the variability of the Treasury revenue under the uniform-price format may be explained by the reduction of the negative correlation between the revenues generated during an auction by the large and small banks.

${ }^{49}$ Our simulations actually suggest that the revenue of the French Treasury would be larger at $66.8 \%$ of the auctions in our sample, if they were conducted with the uniform pricing rule instead of the discriminatory format.
} 
the conclusion holds in a neighborhood of the estimated parameters. ${ }^{50}$ Monte Carlo simulations also indicate that similar conclusions may be obtainable under a single source of either risk aversion or informational asymmetry. In the case of the French Treasury auction, however, it appears that, given the estimated values of the structural parameters, both informational and risk aversion asymmetries are necessary.

\section{Conclusion}

The purpose of this paper was to test whether bidders in French Treasury auctions are symmetric, and to determine which of the discriminatory or uniform-price format is the most appropriate in this context. To address these questions, we generalized the share auction model with supply uncertainty of Wang and Zender (2002) to account for informational and risk aversion asymmetries. The structural estimation of the model suggests that participants in French Treasury auctions may be divided in two distinct groups, differentiated by their level of risk aversion, and the quality of their information about the value of the security to be sold. A counter-factual analysis also indicates that, under our model's hypotheses, both the French Treasury and the auctions' participants would have benefited, if the auctions in our sample had been conducted under the uniform-price format instead of the discriminatory format.

This result contrasts with a previous structural analysis conducted in France under the symmetry and risk neutrality assumptions. Indeed, Fevrier et al. (2002) find that discriminatory auctions increase the revenue of the French Treasury. Failure to account for potential risk aversion and asymmetries in Treasury auctions, therefore appears to have serious consequences, as it may, for instance, lead to conclude in favor of the incorrect auction format.

Moreover, although specific to the French Treasury, our analysis may be considered of general interest. Indeed, just like in France, most Treasury auctions around the world seem to involve asymmetric bidders, and are conducted with the discriminatory format. Our results suggest that in such context, the determination of the best pricing rule crucially depends on the underlying structural parameters of the model. The theoretic and econometric methodology developed

\footnotetext{
${ }^{50}$ More precisely, given our parameter estimates, we are able to construct the following $95 \%$ confidence intervals for the gains of the different participants after shifting to the uniform-price format: revenue gains by the French Treasury $[2.761 \%, 7.328 \%]$, utility gains by large banks $[2.887 \%, 9.841 \%]$, utility gains by small banks $[4.708 \%, 8.617 \%]$.
} 
in the present paper could therefore be applied to other Treasury auctions to test in each individual case which auction mechanism appears to be the most advantageous to the auctioneer.

To conclude, it is interesting to note that the spirit of our results is somewhat consistent with the basic intuition of Friedman (1960). Indeed, Friedman suggested that the uniform-price format was preferable as it may provide an incentive to small and/or uniformed bidders to participate. Although participation is considered to be fully exogenous in our model, we find that shifting to the uniform-price format may incite less informed and more risk averse participants to behave more aggressively. As it turns out, this increased competition may benefit not only the Treasury, but also the auctions' participants.

\section{References}

Anton J.J. and D.A. Yao, 1992: "Coordination in Split-Award Auctions", Quarterly Journal of Economics, 107.2.

Armantier O., Florens J-P. and J-F. Richard, 1998: "Equilibre Approximatif et Règle Intuitive : une Application aux Appels d'Offres dans l'Industrie Spatiale", Economie et Prévision, 1.2., 179-190.

Armantier O., Florens J-P. and J-F. Richard, 2001: "Nash Equilibrium Approximation in Games of Incomplete Information", Working Paper, SUNY Stony Brook, available at http://www.sunysb.edu/economics/research/jour_wp.html.

Armantier O., Florens J-P. and J-F. Richard 2002: "Game Theoretic Models of Incomplete Information: Constrained Equilibrium and Simulation", SUNY Stony Brook, available at http://www.sunysb.edu/economics/research/jour_wp.html.

Athey S. and P. Haile, 2002: "Identification in Standard Auction Models", Econometrica, 70 (6), November 2002, 2107-2140.

Ausubel L.M. and P. Cramton, 2002: "Demand Reduction and Inefficiency in Multi-Unit Auctions", Working Paper, University of Maryland.

Back K. and J. Zender, 1993: "Auctions of Divisible Goods: On the Rationale for the Treasury Experiment", Review of Financial Studies 6, 733-764.

Back K. and J. Zender, 2001: "Auctions of Divisible Goods with endogenous supply", Economics Letter 73, 29-34.

Berg S.A., Boukai B. and M. Landsberger 1999: "Bid Functions for Treasury 
Securities; Across Countries Comparison", Working Paper, Haifa University.

Bjonnes G. H., 2001: "Bidder Behavior in Uniform Price Auctions: Evidence from Norwegian Treasury Bond Auctions", Working Paper, Norvegian School of Management.

Bikhchandani S. and C. Huang, 1993: "The Economics of Treasury Security Markets", Journal of Economic Perspectives, 7, 117-134.

Campo S., Guerre E., Perrigne I. and Q. Vuong, 2002: "Semiparametric Estimation of First-Price Auctions with Risk Averse Bidders", Working Paper, University of Southern California.

Capen E.C., Clapp R.B. and W.M. Campbell, 1971: "Competitive Bidding in High Risk Situations", Journal of Petroleum Technology, June, 23, p.641-53.

Castellanos S. and M. Oviedo, 2002: "Optimal Bidding in the Mexican Treasury Securities Primary Auctions: A Structural Econometrics Approach", Working Paper, Yale University.

Carasco M. and Florens J.-P., 2002: "Simulation Based Method of Moments and Efficiency", Journal of Business 83 Economic Statistics special issue for the 20th Anniversary of GMM, Vol. 20, No. 4, 482-492.

Das S. and R. Sundaram, 1996: "Auction Theory: A Summary with Applications and Evidence from the Treasury Markets", Financial Markets, Institutions and Instruments, v5(5), 1-36.

Donald S. and H. Paarsch, 1993: "Piecewise Pseudo-Maximum Likelihood Estimation in Empirical Models of Auctions", International Economic Review, 34, 121-148.

Donald S. and H. Paarsch, 1996: "Identification, Estimation and Testing in Parametric Empirical Models of Auctions within the IPV", Econometric Theory, $12,517-567$.

Eklöf M., 2003: "Assessing Social Costs of Inefficient Procurement Design", Working Paper.

Fevrier P., Preguet R. and M. Visser, 2002: "Econometrics of Share Auctions", Working Paper, CREST, Paris.

Florens J-P., Protopopescu C. and J-F. Richard, 2002, "Inference in a Class of Game Theoretic Models", Mimeo, University of Pittsburgh.

Florens J.-P. and E. Sbaï, 2002: "Identification in Empirical Games", Working Paper, GREMAQ, University of Toulouse.

Friedman M., 1960: "A Program for Monetary Stability", New York, NY : Fordham University Press.

Gourieroux C. and A. Monfort, 1995: "Simulation Based Econometric Meth- 
ods", Louvain, CORE Lectures Series; Oxford Univ. Press.

Guerre E., Perrigne I. and Q. Vuong, 2000: "Optimal Nonparametric Estimation of First-Price Auctions", Econometrica, 68, 525-574.

Hortaçsu A., 2002a: "Mechanism Choice and Strategic Bidding in Divisible Good Auctions: An Empirical Analysis of the Turkish Treasury Auction Market", Working Paper, Stanford University.

Hortaçsu A., 2002b: "Bidding Behavior in Divisible Good Auctions: Theory and Evidence from the Turkish Treasury Auction Market", Working Paper, Stanford University.

Jegadeesh N., 1993: "Treasury Auction Bids and the Salomon Squeeze", Journal of Finance, vol. 48, 1403-19.

Judd K., 1998: "Numerical Method in Economics", MIT Press, Cambridge Mass.

Kagel J.H., 1995: "Auctions: A Survey of Experimental Research," in The Handbook of Experimental Economics, edited by J.H. Kagel and A.E. Roth, Princeton University Press.

Kearfott R. B., 1996: "Rigorous Global Search: Continuous Problems", Kluwer, Dordrecht.

Klemperer P., 2000: "The Economic Theory of Auctions", (ed.), Edward Elgar (pub.), Cheltenhaum, UK.

Klemperer P. and M. Meyer, 1989: "Supply Function Equilibria in Oligopoly under Uncertainty", Econometrica, 57(6), 1243-77.

Laffont J.-J., Ossard O. and Q. Vuong, 1995: "Econometrics of First Price Auctions", Econometrica, 63, No. 4, 953-980.

McFadden D., 1989: "A Method of Simulated Moments for Estimation of Discrete Response Models without Numerical Integration", Econometrica, 57, 9951026.

Malvey P.F. and C.F. Archibald, 1998: "Uniform-Price Auctions: Update of the Treasury Experience", U.S. Treasury.

Mester L.J., 1995: "There's More than One Way to Sell a Security: The Treasury's Auction Experiment", Federal Reserve Bank of Philadelphia Business Review, July/August, p.3-17.

Nandi S., 1997: "Treasury Auctions : What Do the Recent Models and Results Tell Us?", Federal Reserve Bank of Atlanta Economic Review, Fourth Quarter.

Neumaier A., 1990: "Interval methods for systems of equations", Cambridge University Press, Cambridge.

Newey W.K. and K. West, 1987: "Hypotheses Testing with Efficient Method 
of Moments Testing", International Economic Review, 28: 777-787.

Nyborg K.G and S. Sundaresan, 1996: "Discriminatory versus Uniform Treasury Auctions: Evidence from When-Issued Transactions", Journal of Financial Economics, Vol 42:1, 63-105.

Paarsch H., 1992: "Deciding between the Common and Private Value Paradigms in Empirical Models of Auctions", Journal of Econometrics, 51, 191-215.

Pakes A. and D. Pollard, 1989: "Simulation and the Asymptotics of Optimization Estimators", Econometrica, 57, 1027-1057.

Simon D., 1994: "The Treasury's Experiment with Single-Price Auctions in the Mid 1970's: Winner's or Taxpayer's curse?", Review of Economics and Statistics, $76,754-760$.

Singleton K., 1985: "Testing Specifications of Economic Agents' Intertemporal Optimum Problems in the Presence of Alternative Models", Journal of Econometrics 30, November 1985, 391-413.

Tenorio R., 1993: "Revenue Equivalence and Bidding Behavior in a MultiUnit Auction Market: An Empirical Analysis", The Review of Economics and Statistics, Vol. 75, No. 2., 302-314.

Umlauf S., 1993: "An Empirical Study of the Mexican Treasury bill Auctions", Journal of Financial Economics, 33, 313-40.

Viswanathan S. and J. Wang, 2000: "Auctions with When-Issued Trading : A Model of the US Treasury Markets", Working Paper, Duke University.

Wang J. and J. Zender, 2002: "Auctioning Divisible Goods", Economic Theory, vol. 19, 673-705.

Wilson R., 1979: "Auctions of Shares", The Quarterly Journal of Economics, 93, 675-689. 


\section{Appendix: Identification of the Model}

To address the issue of the model's identification, we built on the general procedure proposed by Florens and Sbaï (2002) for auction models with risk averse bidders. The procedure is based on the local identification principle. Before we define this notion more precisely, let us recall that the parameters of interest are the vectors $\beta=\left(\delta_{0}, \delta_{1}, \delta_{2}, \delta_{3}, \sigma_{V}\right)$ which characterizes the distribution of the true value of the security, $\left(\sigma_{1}, \sigma_{2}\right)$ the variances of the bidders' private signals, and $\lambda=\left(\lambda_{1}, \lambda_{2}\right)$ the risk aversion parameters. Let us also denote $\theta=\left(\beta, \sigma_{1}, \sigma_{2}\right)$.

Definition 13.1. The parameters $(\theta, \lambda)$ and $\left(\theta_{*}, \lambda_{*}\right)$ are observationally equivalent $\left((\theta, \lambda) \sim\left(\theta_{*}, \lambda_{*}\right)\right)$ iff $G=G_{*}$, where $G=F_{\theta} \circ\left(\varphi^{\theta, \lambda}\right)^{-1}$ and $G_{*}=F_{\theta_{*}} \circ\left(\varphi^{\theta_{*}, \lambda_{*}}\right)^{-1}$ are the c.d.f. of the observed actions of a representative player, and $\left(\varphi^{\theta, \lambda}, \varphi^{\theta_{*}, \lambda_{*}}\right)$ belong to the set of admissible strategies.

Definition 13.2. The parameters $(\theta, \lambda) \in \mathbb{R}^{9}$ are locally identified iff there exists a neighborhood $\mathcal{V}(\theta, \lambda)$ of $(\theta, \lambda)$ in $\mathbb{R}^{9}$ such that

$$
\forall\left(\theta_{*}, \lambda_{*}\right) \in \mathcal{V}(\theta, \lambda),\left(\theta_{*}, \lambda_{*}\right) \sim(\theta, \lambda) \Longrightarrow\left(\theta_{*}, \lambda_{*}\right)=(\theta, \lambda)
$$

Lemma 13.3. $\left(\theta_{*}, \lambda_{*}\right)$ is observationally equivalent to $(\theta, \lambda)$ iff

$$
F_{\theta_{*}}-G \circ \varphi^{\theta_{*}, \lambda_{*}}=0
$$

The proof is trivial: if $\left(\theta_{*}, \lambda_{*}\right) \sim(\theta, \lambda)$ then $G=G_{*}$, and $F_{\theta_{*}}=G_{*} \circ \varphi^{\theta_{*}, \lambda_{*}}=$ $G \circ \varphi^{\theta_{*}, \lambda_{*}}$. Conversely, equation (13.1) implies $G=G_{*}$ from the definition of $G_{*}$.

The next theorem is an adaptation of a result in Florens and Sbaï (2002) to our model.

Theorem 13.4. The asymmetric model $\left(\varphi_{1}^{\theta, \lambda}, \varphi_{2}^{\theta, \lambda}, \theta, \lambda\right)$, where $\varphi_{l}^{\theta, \lambda}$ is a strategy function for players in group $l=1,2$, is locally identified if the operator

$$
T_{\theta, \lambda}=\partial_{(\theta, \lambda)} F_{\theta}-\sum_{l=1}^{2}\left\{\frac{\partial_{s_{l}} F_{\theta}}{\partial_{s_{l}} \varphi_{l}^{\theta, \lambda}} \cdot \partial_{(\theta, \lambda)} \varphi_{l}^{\theta, \lambda}\right\}
$$

is one to one $\forall(\theta, \lambda) \in \mathbb{R}^{9}$, where $F_{\theta}$ is the joint distribution of $\left(s_{1}, s_{2}\right)$ a pair of signals of a representative player in each group. 
Proof: Consider the application

$$
\begin{aligned}
A & : \mathbb{R}^{9} \times \mathbb{R}^{9} \longrightarrow \mathbb{R} \\
{\left[(\theta, \lambda) ;\left(\theta_{*}, \lambda_{*}\right)\right] } & \longmapsto A\left((\theta, \lambda) ;\left(\theta_{*}, \lambda_{*}\right)\right)=F_{\theta *}-G \circ \varphi^{\theta_{*}, \lambda_{*}}
\end{aligned}
$$

where $\varphi^{\theta_{*}, \lambda_{*}}=\left(\varphi_{1}^{\theta_{*}, \lambda_{*}}, \varphi_{2}^{\theta_{*}, \lambda_{*}}\right)$, and $G=F_{\theta} \circ\left(\varphi^{\theta, \lambda}\right)^{-1}$ is the c.d.f. of the observed pair of actions of a representative players of each group.

Note that $A((\theta, \lambda) ;(\theta, \lambda))=0$. It follows from the implicit function theorem that, if the differential of $A(\cdot)$ w.r.t. $\left(\theta_{*}, \lambda_{*}\right)$ is injective at $((\theta, \lambda) ;(\theta, \lambda))$, then there exists a neighborhood $\mathcal{V}(\theta, \lambda)$ of $(\theta, \lambda)$ such that $\left(\theta_{*}, \lambda_{*}\right)=(\theta, \lambda)$ is the unique solution to the equation $A\left((\theta, \lambda) ;\left(\theta_{*}, \lambda_{*}\right)\right)=0$ for $\left(\theta_{*}, \lambda_{*}\right) \in \mathcal{V}(\theta, \lambda)$. In this case, it follows from Lemma 13.1 that $(\theta, \lambda)$ is locally identified. The differential of $A(\cdot)$ w.r.t. $\left(\theta_{*}, \lambda_{*}\right)$ evaluated at $((\theta, \lambda) ;(\theta, \lambda))$ is characterized by the operator

$$
\partial_{(\theta, \lambda)} F_{\theta}-\partial_{(\theta, \lambda)}\left[G \circ \varphi^{\theta, \lambda}\right]=\partial_{(\theta, \lambda)} F_{\theta}-\partial_{(\theta, \lambda)}\left[G\left(\varphi_{1}^{\theta, \lambda}, \varphi_{2}^{\theta, \lambda}\right)\right],
$$

which may also be written

$$
\partial_{(\theta, \lambda)} F_{\theta}-\sum_{l=1}^{2} \partial_{\varphi_{l}^{\theta, \lambda}} G\left(\varphi_{1}^{\theta, \lambda}, \varphi_{2}^{\theta, \lambda}\right) . \partial_{(\theta, \lambda)} \varphi_{l}^{\theta, \lambda}
$$

Moreover, we know that $G \circ \varphi^{\theta, \lambda}=F_{\theta}$, which implies that $\partial_{s_{l}} \varphi_{l}^{\theta, \lambda} \cdot \partial_{\varphi_{l}^{\theta, \lambda}} G\left(\varphi^{\theta, \lambda}\right)=$ $\partial_{s_{l}} F_{\theta}$ and

$$
\partial_{\varphi_{l}^{\theta, \lambda}} G \circ \varphi^{\theta, \lambda}=\frac{\partial_{s_{l}} F_{\theta}}{\partial_{s_{l}} \varphi_{l}^{\theta, \lambda}}
$$

Note that the CSEs are fully defined by a parameter $d_{l}$ which may be expressed as a function of $(\theta, \lambda)$. Therefore, $\varphi_{l}^{\theta, \lambda}$, the strategy function of players in group $l$, may be written as $\varphi_{d_{l(\theta, \lambda)}}$. Then, our model will be identified if the following operator is invertible:

$$
T_{\theta, \lambda}=\partial_{(\theta, \lambda)} F_{\theta}-\sum_{l=1}^{2}\left\{\frac{\partial_{s_{l}} F_{\theta}}{\partial_{s_{l}} \varphi_{d_{l(\theta, \lambda)}}} . \partial_{(\theta, \lambda)} \varphi_{d_{l}(\theta, \lambda)}\right\} .
$$

Since the distributions and strategies belong to known parametric families, we can easily derive $\partial_{s_{l}} F_{\theta}, \partial_{(\theta, \lambda)} F_{\theta}$ and $\partial_{s_{l}} \varphi_{d_{l(\theta, \lambda)}}$. The derivation of $\partial_{(\theta, \lambda)} \varphi_{d_{l}(\theta, \lambda)}$, however is usually not as straightforward, since $d_{l}(\theta, \lambda)$ is typically an implicit function of $(\theta, \lambda)$. As suggested in Florens and Sbaï (2002), we can derive $\partial_{(\theta, \lambda)} \varphi_{d_{l}(\theta, \lambda)}$ in this situation by 
applying the Implicit Function Theorem to the first order conditions defining the CSE. Following Florens and Sbaï (2002), we find that

$$
\partial_{(\theta, \lambda)} \varphi_{d(\theta, \lambda)}=\left[\partial_{(\theta, \lambda)} \varphi_{d_{1}(\theta, \lambda)}, \partial_{(\theta, \lambda)} \varphi_{d_{2}(\theta, \lambda)}\right]^{\prime}=\partial_{d} \varphi_{d(\theta, \lambda)} . \partial_{(\theta, \lambda)} d(\theta, \lambda)
$$

where

$$
\begin{aligned}
\partial_{(\theta, \lambda)} d(\theta, \lambda)= & -\left\{\partial_{d}\left[\begin{array}{c}
\partial_{d_{1}} \tilde{U}_{1}\left(d_{1}, d_{2}, \theta, \lambda_{1}\right) \\
\partial_{d_{2}} \tilde{U}_{2}\left(d_{1}, d_{2}, \theta, \lambda_{2}\right)
\end{array}\right]\right\}^{-1} . \partial_{(\theta, \lambda)}\left[\begin{array}{c}
\partial_{d_{1}} \tilde{U}_{1}\left(d_{1}, d_{2}, \theta, \lambda_{1}\right) \\
\partial_{d_{2}} \tilde{U}_{2}\left(d_{1}, d_{2}, \theta, \lambda_{2}\right)
\end{array}\right] \\
= & -\left[\begin{array}{cc}
\partial_{d_{1}}^{2} \tilde{U}_{1}\left(d_{1}, d_{2}, \theta, \lambda_{1}\right) & \partial_{d_{2}} \partial_{d_{1}} \tilde{U}_{1}\left(d_{1}, d_{2}, \theta, \lambda_{1}\right) \\
\partial_{d_{1}} \partial_{d_{2}} \tilde{U}_{2}\left(d_{1}, d_{2}, \theta, \lambda_{2}\right) & \partial_{d_{2}}^{2} \tilde{U}_{2}\left(d_{1}, d_{2}, \theta, \lambda_{2}\right)
\end{array}\right]^{-1} \\
& . \partial_{(\theta, \lambda)}\left[\partial_{d_{1}} \tilde{U}_{1}\left(d_{1}, d_{2}, \theta, \lambda_{1}\right), \partial_{d_{2}} \tilde{U}_{2}\left(d_{1}, d_{2}, \theta, \lambda_{2}\right)\right] .
\end{aligned}
$$

Since the expected utility is a known parametric function, the derivatives in the previous expression may be calculated without difficulty in most practical applications. Once, $\partial_{(\theta, \lambda)} \varphi_{d_{l}(\theta, \lambda)}$ has been determined, we can then verify whether the operator $T_{\theta, \lambda}$ is invertible. 


\begin{tabular}{|c|c|c|c|c|}
\hline & $\begin{array}{r}\text { St } \\
\text { (Average pe }\end{array}$ & $\begin{array}{r}\text { Table } 1 \\
\text { nmary Sta } \\
\text { uction unless me }\end{array}$ & $\begin{array}{l}\text { ics } \\
\text { ed otherwise) }\end{array}$ & \\
\hline & & Total & OAT & BTAN \\
\hline Number $\mathrm{c}$ & auctions & 118 & 60 & 58 \\
\hline & Total & $\begin{array}{l}19.025 \\
(0.797)\end{array}$ & $\begin{array}{l}18.983 \\
(0.871)\end{array}$ & $\begin{array}{l}19.069 \\
(0.686)\end{array}$ \\
\hline $\begin{array}{l}\text { Number of } \\
\text { Competitive }\end{array}$ & Large Banks & $\begin{array}{c}4.508 \\
(1.443) \\
\end{array}$ & $\begin{array}{c}4.800 \\
(1.542) \\
\end{array}$ & $\begin{array}{c}4.207 \\
(1.237) \\
\end{array}$ \\
\hline Bidders & Small Banks & $\begin{array}{r}14.568 \\
(1.536) \\
\end{array}$ & $\begin{array}{c}14.217 \\
(1.603) \\
\end{array}$ & $\begin{array}{c}14.931 \\
(1.366) \\
\end{array}$ \\
\hline $\mathrm{Yi}$ & & $\begin{array}{c}4.826 \\
(1.186)\end{array}$ & $\begin{array}{c}5.492 \\
(1.191)\end{array}$ & $\begin{array}{c}4.138 \\
(0.679)\end{array}$ \\
\hline $\begin{array}{l}\text { Mat } \\
\text { (in c }\end{array}$ & & $\begin{array}{c}3,541.627 \\
(3,462.798)\end{array}$ & $\begin{array}{c}5,746.683 \\
(3,391.702)\end{array}$ & $\begin{array}{l}1,260.534 \\
(570.006)\end{array}$ \\
\hline $\begin{array}{l}\text { Quantity } \\
\text { (in Milli }\end{array}$ & $\begin{array}{l}\text { upplied } \\
\text { ( Euros) }\end{array}$ & $\begin{array}{l}1,559.500 \\
(959.273)\end{array}$ & $\begin{array}{c}1,535.544 \\
(1,044.719)\end{array}$ & $\begin{array}{l}1,584.283 \\
(816.756)\end{array}$ \\
\hline $\begin{array}{l}\text { Non Comp } \\
\text { (in Milli }\end{array}$ & $\begin{array}{l}\text { itive Bids } \\
\text { Euros) }\end{array}$ & $\begin{array}{c}44.122 \\
(59.100) \\
\end{array}$ & $\begin{array}{c}47.640 \\
(63.302) \\
\end{array}$ & $\begin{array}{c}40.611 \\
(57.610) \\
\end{array}$ \\
\hline Stop-Or & Price* & $\begin{array}{l}101.163 \\
(6.975) \\
\end{array}$ & $\begin{array}{c}102.476 \\
(8.898) \\
\end{array}$ & $\begin{array}{l}99.804 \\
(3.738) \\
\end{array}$ \\
\hline $\begin{array}{c}\text { Average } \\
\text { Price Paid }\end{array}$ & Large Banks & $\begin{array}{l}101.185 \\
(5.985)\end{array}$ & $\begin{array}{l}102.508 \\
(6.130)\end{array}$ & $\begin{array}{l}99.816 \\
(3.401)\end{array}$ \\
\hline $\begin{array}{c}\text { Per Unit } \\
\text { Purchased }\end{array}$ & Small Banks & $\begin{array}{l}101.180 \\
(12.482)\end{array}$ & $\begin{array}{l}102.501 \\
(11.310)\end{array}$ & $\begin{array}{l}99.813 \\
(3.774)\end{array}$ \\
\hline Share & Total & $\begin{array}{c}0.638 \\
(0.006) \\
\end{array}$ & $\begin{array}{c}0.645 \\
(0.006) \\
\end{array}$ & $\begin{array}{c}0.625 \\
(0.005) \\
\end{array}$ \\
\hline $\begin{array}{l}\text { Awarded to } \\
\text { Large Banks }\end{array}$ & Per Bank & $\begin{array}{c}0.167 \\
(0.121)\end{array}$ & $\begin{array}{c}0.168 \\
(0.096)\end{array}$ & $\begin{array}{c}0.166 \\
(0.098)\end{array}$ \\
\hline Share & Total & $\begin{array}{c}0.362 \\
(0.007)\end{array}$ & $\begin{array}{c}0.355 \\
(0.008)\end{array}$ & $\begin{array}{c}0.375 \\
(0.006)\end{array}$ \\
\hline $\begin{array}{l}\text { Awarded to } \\
\text { Small Banks }\end{array}$ & Per Bank & $\begin{array}{c}0.024 \\
(0.042)\end{array}$ & $\begin{array}{c}0.024 \\
(0.048)\end{array}$ & $\begin{array}{c}0.025 \\
(0.041)\end{array}$ \\
\hline $\begin{array}{r}\text { Probability that } \\
\text { Awarded a } \\
\text { Sec }\end{array}$ & $\begin{array}{l}\text { Small Bank is } \\
\text { hare of the } \\
\text { ity }\end{array}$ & 0.643 & 0.645 & 0.640 \\
\hline Highest Price & Large Banks & $\begin{array}{l}101.193 \\
(6.700)\end{array}$ & $\begin{array}{l}102.519 \\
(8.227) \\
\end{array}$ & $\begin{array}{l}99.821 \\
(2.403)\end{array}$ \\
\hline Submitted & Small Banks & $\begin{array}{l}100.922 \\
(11.032)\end{array}$ & $\begin{array}{l}102.360 \\
(13.295)\end{array}$ & $\begin{array}{l}99.419 \\
(3.206)\end{array}$ \\
\hline Per Auction & Total & $\begin{array}{l}1,582.619 \\
(664.794)\end{array}$ & $\begin{array}{l}1,579.370 \\
(535.822)\end{array}$ & $\begin{array}{l}1,585.981 \\
(473.006)\end{array}$ \\
\hline $\begin{array}{c}\text { Revenue } \\
\text { for Treasury }\end{array}$ & $\begin{array}{c}\text { From Large } \\
\text { Banks }\end{array}$ & $\begin{array}{c}989.652 \\
(424.910) \\
\end{array}$ & $\begin{array}{c}994.441 \\
(384.113)\end{array}$ & $\begin{array}{c}984.697 \\
(441.201)\end{array}$ \\
\hline (Million Euros) & $\begin{array}{c}\text { From Small } \\
\text { Banks }\end{array}$ & $\begin{array}{c}592.967 \\
(293.821)\end{array}$ & $\begin{array}{c}584.929 \\
(285.573)\end{array}$ & $\begin{array}{c}601.283 \\
(298.933)\end{array}$ \\
\hline $\begin{array}{c}\text { Total Revenu } \\
\text { During the S }\end{array}$ & $\begin{array}{l}\text { for Treasury } \\
\text { nple Period }\end{array}$ & $186,749.153$ & $94,762.249$ & $91,986.904$ \\
\hline
\end{tabular}




\section{Table 2}

Quantity Supplied to Competitive Bidders

\begin{tabular}{|c|c|c|c|c|c|c|c|c|}
\hline Parameter & $\begin{array}{c}\alpha_{0} \\
\text { (Constant) }\end{array}$ & $\begin{array}{c}\alpha_{1} \\
\text { (MeanBracket) }\end{array}$ & $\begin{array}{c}\alpha_{2} \\
\text { (SpreadBracket) }\end{array}$ & $\begin{array}{c}\alpha_{3} \\
\text { (Maturity) }\end{array}$ & $\begin{array}{c}\alpha_{4} \\
\text { (Yield) }\end{array}$ & $\begin{array}{c}\alpha_{5} \\
\text { (Type) }\end{array}$ & $\sigma_{v}$ & $R^{2}$ \\
\hline \multirow{2}{*}{ Estimates } & $\begin{array}{l}1381.547^{*} \\
(376.208)\end{array}$ & $\begin{array}{l}0.674^{*} \\
(0.106)\end{array}$ & $\begin{array}{c}-0.268 \\
(0.860)\end{array}$ & $\begin{array}{l}-0.201 * \\
(0.029)\end{array}$ & $\begin{array}{c}-353.198^{*} \\
(61.214)\end{array}$ & $\begin{array}{l}1184.680^{*} \\
(186.789)\end{array}$ & $\begin{array}{l}\text { 492.941* } \\
(98.143)\end{array}$ & 0.769 \\
\hline & $\begin{array}{l}1426.927^{*} \\
(351.162)\end{array}$ & $\begin{array}{l}0.681^{*} \\
(0.092)\end{array}$ & . & $\begin{array}{l}-0.193 * \\
(0.032)\end{array}$ & $\begin{array}{c}-376.245^{*} \\
(55.007)\end{array}$ & $\begin{array}{l}1208.732^{*} \\
(182.404)\end{array}$ & $\begin{array}{c}475.207^{*} \\
(96.651)\end{array}$ & 0.765 \\
\hline
\end{tabular}

Number of Observations: 118

* Indicates parameters significant at a 5\% significance level.

Standard deviations are in parenthesis.

\begin{tabular}{|c|c|c|}
\hline \multicolumn{3}{|c|}{$\begin{array}{c}\text { Table } 3 \\
\text { Structural Parameter Estimates }\end{array}$} \\
\hline $\begin{array}{c}\delta_{0} \\
\text { (Constant) }\end{array}$ & $\begin{array}{l}80.783^{*} \\
(14.721)\end{array}$ & $\begin{array}{l}81.165^{*} \\
(14.913) \\
\end{array}$ \\
\hline $\begin{array}{c}\delta_{1} \\
\text { (Yield) }\end{array}$ & $\begin{array}{l}4.822^{*} \\
(1.726)\end{array}$ & $\begin{array}{l}4.782^{*} \\
(1.697)\end{array}$ \\
\hline $\begin{array}{c}\delta_{2} \\
\text { (Maturity) }\end{array}$ & $\begin{array}{l}-7.219 \mathrm{E}-4^{*} \\
(2.308 \mathrm{E}-5)\end{array}$ & $\begin{array}{r}-7.223 \mathrm{E}-4^{*} \\
(2.160 \mathrm{E}-5)\end{array}$ \\
\hline $\begin{array}{c}\delta_{3} \\
\text { (Type) }\end{array}$ & $\begin{array}{l}-0.592 \\
(2.851)\end{array}$ & 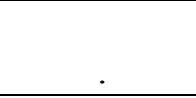 \\
\hline $\begin{array}{c}\sigma_{V} \\
\text { (Standard Deviation of True Values) }\end{array}$ & $\begin{array}{l}0.630^{*} \\
(0.010) \\
\end{array}$ & $\begin{array}{l}0.632^{*} \\
(0.010) \\
\end{array}$ \\
\hline $\begin{array}{c}\sigma_{1} \\
\text { (Standard Deviation of Large Banks Private Signals) }\end{array}$ & $\begin{array}{l}0.071^{*} \\
(0.023) \\
\end{array}$ & $\begin{array}{l}0.070^{*} \\
(0.021) \\
\end{array}$ \\
\hline $\begin{array}{c}\sigma_{2} \\
\text { (Standard Deviation of Small Banks Private Signals) }\end{array}$ & $\begin{array}{l}0.172^{*} \\
(0.058)\end{array}$ & $\begin{array}{l}0.178^{*} \\
(0.063)\end{array}$ \\
\hline $\begin{array}{c}\lambda_{1} \\
\text { (CARA Parameter for Large Banks) }\end{array}$ & $\begin{array}{l}7.615 \mathrm{E}-8^{*} \\
(7.604 \mathrm{E}-9)\end{array}$ & $\begin{array}{l}5.732 \mathrm{E}-8^{*} \\
(4.908 \mathrm{E}-9)\end{array}$ \\
\hline $\begin{array}{c}\lambda_{2} \\
\text { (CARA Parameter for Small Banks) }\end{array}$ & $\begin{array}{l}8.774 \mathrm{E}-5^{*} \\
(2.580 \mathrm{E}-7)\end{array}$ & $\begin{array}{l}6.907 \mathrm{E}-6 * \\
(1.401 \mathrm{E}-7)\end{array}$ \\
\hline \multicolumn{3}{|c|}{ Number of Observations: 40,496} \\
\hline
\end{tabular}




\begin{tabular}{|c|c|c|c|c|}
\hline \multicolumn{5}{|c|}{$\begin{array}{l}\text { Simulation of Discriminatory Treasury Auctions } \\
\text { (Average per auction unless mentioned otherwise) }\end{array}$} \\
\hline & & Total & OAT & BTAN \\
\hline \multicolumn{2}{|c|}{ True Value } & 101.772 & 103.125 & 100.381 \\
\hline \multicolumn{2}{|c|}{ Stop-Out-Price* } & $\begin{array}{l}101.162 \\
(6.981) \\
\end{array}$ & $\begin{array}{l}102.474 \\
(9.325) \\
\end{array}$ & $\begin{array}{l}99.805 \\
(3.848) \\
\end{array}$ \\
\hline \multirow{2}{*}{$\begin{array}{l}\text { Average } \\
\text { Price Paid } \\
\text { Per Unit } \\
\text { Purchased* }\end{array}$} & Large Banks & $\begin{array}{l}101.186 \\
(6.037)\end{array}$ & $\begin{array}{l}102.508 \\
(5.878)\end{array}$ & $\begin{array}{l}99.818 \\
(3.769) \\
\end{array}$ \\
\hline & Small Banks & $\begin{array}{l}101.179 \\
(13.546)\end{array}$ & $\begin{array}{l}102.501 \\
(10.871)\end{array}$ & $\begin{array}{l}99.812 \\
(3.976)\end{array}$ \\
\hline \multirow{2}{*}{$\begin{array}{c}\text { Share } \\
\text { Awarded to } \\
\text { Large Banks }\end{array}$} & Total & $\begin{array}{c}0.631 \\
(0.005)\end{array}$ & $\begin{array}{c}0.636 \\
(0.006)\end{array}$ & $\begin{array}{c}0.624 \\
(0.004)\end{array}$ \\
\hline & Per Bank & $\begin{array}{c}0.163 \\
(0.129)\end{array}$ & $\begin{array}{c}0.165 \\
(0.104)\end{array}$ & $\begin{array}{c}0.164 \\
(0.136)\end{array}$ \\
\hline \multirow{2}{*}{$\begin{array}{c}\text { Share } \\
\text { Awarded to } \\
\text { Small Banks }\end{array}$} & Total & $\begin{array}{c}0.369 \\
(0.007)\end{array}$ & $\begin{array}{c}0.364 \\
(0.008)\end{array}$ & $\begin{array}{c}0.376 \\
(0.005)\end{array}$ \\
\hline & Per Bank & $\begin{array}{c}0.028 \\
(0.046) \\
\end{array}$ & $\begin{array}{c}0.027 \\
(0.051) \\
\end{array}$ & $\begin{array}{c}0.025 \\
(0.039) \\
\end{array}$ \\
\hline \multicolumn{2}{|c|}{$\begin{array}{l}\text { Probability that a Small Bank is } \\
\text { Awarded a Share of the Security }\end{array}$} & 0.642 & 0.646 & 0.639 \\
\hline \multirow{2}{*}{$\begin{array}{l}\text { Highest Price } \\
\text { Submitted* }\end{array}$} & Large Banks & $\begin{array}{l}101.204 \\
(6.725)\end{array}$ & $\begin{array}{l}102.520 \\
(8.239)\end{array}$ & $\begin{array}{l}99.831 \\
(2.386)\end{array}$ \\
\hline & Small Banks & $\begin{array}{l}100.945 \\
(11.131)\end{array}$ & $\begin{array}{l}102.340 \\
(13.108)\end{array}$ & $\begin{array}{l}99.444 \\
(3.180)\end{array}$ \\
\hline \multirow{2}{*}{$\begin{array}{c}\text { Profit } \\
\text { Per Bank } \\
\text { (Million Euros) }\end{array}$} & Large Banks & $\begin{array}{c}1.267 \\
(0.631)\end{array}$ & $\begin{array}{c}1.328 \\
(0.716)\end{array}$ & $\begin{array}{c}1.215 \\
(0.582)\end{array}$ \\
\hline & Small Banks & $\begin{array}{c}0.141 \\
(0.125) \\
\end{array}$ & $\begin{array}{c}0.156 \\
(0.132) \\
\end{array}$ & $\begin{array}{c}0.128 \\
(0.116) \\
\end{array}$ \\
\hline \multirow{2}{*}{$\begin{array}{l}\text { Expected } \\
\text { Utility }\end{array}$} & Large Banks & $\begin{array}{l}-0.943 \\
(0.013)\end{array}$ & $\begin{array}{l}-0.939 \\
(0.013)\end{array}$ & $\begin{array}{l}-0.945 \\
(0.014) \\
\end{array}$ \\
\hline & Small Banks & $\begin{array}{l}-0.468 \\
(0.023)\end{array}$ & $\begin{array}{l}-0.437 \\
(0.022)\end{array}$ & $\begin{array}{l}-0.485 \\
(0.024)\end{array}$ \\
\hline \multirow{2}{*}{$\begin{array}{l}\text { Percentage of } \\
\text { Issue Awarded } \\
\text { Subject to the } \\
\text { Winner's Curse }\end{array}$} & Large Banks & $\begin{array}{c}0.085 \\
(0.091) \\
\end{array}$ & $\begin{array}{c}0.083 \\
(0.099) \\
\end{array}$ & $\begin{array}{c}0.086 \\
(0.087) \\
\end{array}$ \\
\hline & Small Banks & $\begin{array}{c}0.010 \\
(0.004) \\
\end{array}$ & $\begin{array}{l}0.009 \\
(0.05) \\
\end{array}$ & $\begin{array}{c}0.012 \\
(0.004) \\
\end{array}$ \\
\hline \multirow{3}{*}{$\begin{array}{l}\text { Per Auction } \\
\text { Revenue } \\
\text { For Treasury } \\
\text { (Million Euros) }\end{array}$} & Total & $\begin{array}{l}1,583.601 \\
(594.126)\end{array}$ & $\begin{array}{l}1,581.641 \\
(553.246)\end{array}$ & $\begin{array}{l}1,585.629 \\
(603.007)\end{array}$ \\
\hline & $\begin{array}{l}\text { From Large } \\
\text { Banks }\end{array}$ & $\begin{array}{c}882.175 \\
(451.730) \\
\end{array}$ & $\begin{array}{c}883.431 \\
(416.526) \\
\end{array}$ & $\begin{array}{c}880.803 \\
(449.642) \\
\end{array}$ \\
\hline & $\begin{array}{c}\text { From Small } \\
\text { Banks }\end{array}$ & $\begin{array}{c}701.426 \\
(372.631)\end{array}$ & $\begin{array}{c}698.210 \\
(343.202)\end{array}$ & $\begin{array}{c}704.826 \\
(398.155)\end{array}$ \\
\hline \multicolumn{2}{|c|}{$\begin{array}{l}\text { Total Revenue for Treasury } \\
\text { During the Sample Period }\end{array}$} & $186,864.942$ & $94,898.461$ & $91,966.481$ \\
\hline
\end{tabular}




\begin{tabular}{|c|c|c|}
\hline \multicolumn{3}{|c|}{$\begin{array}{c}\text { Table } 5 \\
\text { Parameters of the CSE Bid Function } \\
\text { Discriminatory Auction } \\
\left(\mathrm{N}_{1}=5, \mathrm{~N}_{2}=15 \text {, other exogenous variables are taken at their means }\right) \\
\end{array}$} \\
\hline & Large Banks & Small Banks \\
\hline $\mathrm{d}(0)$ & $9.033 \mathrm{E}-1$ & $4.521 \mathrm{E}-1$ \\
\hline $\mathrm{d}(1)$ & $-1.133 \mathrm{E}-1$ & $-5.534 \mathrm{E}-2$ \\
\hline$d(2)$ & $-1.184 \mathrm{E}-1$ & $-1.621 \mathrm{E}-1$ \\
\hline$d(3)$ & $-1.204 \mathrm{E}-1$ & $-5.087 \mathrm{E}-2$ \\
\hline$d(4)$ & $-8.397 \mathrm{E}-2$ & $-5.945 \mathrm{E}-3$ \\
\hline$d(5)$ & $-6.211 \mathrm{E}-1$ & $-5.381 \mathrm{E}-1$ \\
\hline
\end{tabular}

\begin{tabular}{|c|c|c|c|}
\hline \multicolumn{4}{|c|}{ Table 6 } \\
Convergence Criteria \\
Discriminatory Auction \\
\multicolumn{4}{|c|}{$\left(\mathrm{N}_{1}=5, \mathrm{~N}_{2}=15\right.$, other exogenous variables are taken at their means) } \\
\hline Criteria & $\begin{array}{c}\text { Alternative } \\
\text { CSE }(1)\end{array}$ & $\begin{array}{c}\text { CSE(2) } \\
\text { Used in Estimation }\end{array}$ & $\begin{array}{c}\text { Alternative } \\
\text { CSE(3) }\end{array}$ \\
\hline $\mathrm{C}_{1}$ &. & $9.871 \mathrm{E}-3$ & $4.725 \mathrm{E}-6$ \\
\hline $\mathrm{C}_{2}$ & $1.656 \mathrm{E}-3$ & $2.012 \mathrm{E}-5$ & $8.377 \mathrm{E}-6$ \\
\hline $\mathrm{C}_{3}($ in $\%)$ & 5.328 & 0.052 & 0.050 \\
\hline $\mathrm{C}_{4}$ & $2.307 \mathrm{E}-2$ & $7.365 \mathrm{E}-5$ & $5.952 \mathrm{E}-5$ \\
\hline
\end{tabular}

\begin{tabular}{|c|c|c|}
\hline \multicolumn{3}{|c|}{$\begin{array}{c}\text { Table } 7 \\
\text { Parameters of the CSE Bid Function } \\
\text { Uniform-Price Auction } \\
\left(\mathrm{N}_{1}=5, \mathrm{~N}_{2}=15 \text {, other exogenous variables are taken at their means }\right) \\
\end{array}$} \\
\hline & Large Banks & Small Banks \\
\hline $\mathrm{d}(0)$ & $7.300 \mathrm{E}-1$ & $6.358 \mathrm{E}-1$ \\
\hline$d(1)$ & $-8.074 \mathrm{E}-2$ & $-6.309 \mathrm{E}-2$ \\
\hline$d(2)$ & $-8.467 \mathrm{E}-5$ & $-3.592 \mathrm{E}-2$ \\
\hline$d(3)$ & $-9.087 \mathrm{E}-2$ & $-8.856 \mathrm{E}-2$ \\
\hline$d(4)$ & $-2.648 \mathrm{E}-4$ & $-7.091 \mathrm{E}-3$ \\
\hline$d(5)$ & $-6.836 \mathrm{E}-1$ & $-5.798 \mathrm{E}-1$ \\
\hline
\end{tabular}

\begin{tabular}{|c|c|c|c|}
\hline \multicolumn{4}{|c|}{ Table 8 } \\
Convergence Criteria \\
Uniform-Price Auction \\
\multicolumn{4}{|c|}{$\left(\mathrm{N}_{1}=5, \mathrm{~N}_{2}=15\right.$, other exogenous variables are taken at their means) } \\
\hline Criteria & $\begin{array}{c}\text { Alternative } \\
\text { CSE(1) }\end{array}$ & $\begin{array}{c}\text { CSE(2) } \\
\text { Used in Simulations }\end{array}$ & $\begin{array}{c}\text { Alternative } \\
\text { CSE(3) }\end{array}$ \\
\hline $\mathrm{C}_{1}$ & $\cdot$ & $2.096 \mathrm{E}-2$ & $1.028 \mathrm{E}-6$ \\
\hline $\mathrm{C}_{2}$ & $4.638 \mathrm{E}-4$ & $7.826 \mathrm{E}-6$ & $4.914-6$ \\
\hline $\mathrm{C}_{3}($ in $\%)$ & 6.351 & 0.043 & 0.038 \\
\hline $\mathrm{C}_{4}$ & $6.377 \mathrm{E}-3$ & $1.326 \mathrm{E}-5$ & $9.794 \mathrm{E}-6$ \\
\hline
\end{tabular}




\begin{tabular}{|c|c|c|c|c|}
\hline \multicolumn{5}{|c|}{$\begin{array}{l}\text { Simulation of Uniform-Price Treasury Auctions } \\
\text { (Average per auction unless mentioned otherwise) }\end{array}$} \\
\hline & & Total & $\mathrm{OAT}$ & BTAN \\
\hline \multicolumn{2}{|c|}{ True Value } & 101.772 & 103.125 & 100.381 \\
\hline \multicolumn{2}{|c|}{ Stop-Out-Price* } & $\begin{array}{l}101.184 \\
(7.782) \\
\end{array}$ & $\begin{array}{l}102.506 \\
(10.633)\end{array}$ & $\begin{array}{l}99.817 \\
(4.420) \\
\end{array}$ \\
\hline \multirow{2}{*}{$\begin{array}{c}\text { Share } \\
\text { Awarded to } \\
\text { Large Banks }\end{array}$} & Total & $\begin{array}{c}0.447 \\
(0.018)\end{array}$ & $\begin{array}{c}0.449 \\
(0.019)\end{array}$ & $\begin{array}{c}0.443 \\
(0.016)\end{array}$ \\
\hline & Per Bank & $\begin{array}{c}0.100 \\
(0.116)\end{array}$ & $\begin{array}{c}0.102 \\
(0.106)\end{array}$ & $\begin{array}{c}0.097 \\
(0.128)\end{array}$ \\
\hline \multirow{2}{*}{$\begin{array}{c}\text { Share } \\
\text { Awarded to } \\
\text { Small Banks }\end{array}$} & Total & $\begin{array}{c}0.553 \\
(0.003)\end{array}$ & $\begin{array}{c}0.550 \\
(0.003)\end{array}$ & $\begin{array}{c}0.557 \\
(0.003)\end{array}$ \\
\hline & Per Bank & $\begin{array}{c}0.032 \\
(0.031)\end{array}$ & $\begin{array}{c}0.029 \\
(0.030)\end{array}$ & $\begin{array}{c}0.033 \\
(0.033)\end{array}$ \\
\hline \multicolumn{2}{|c|}{$\begin{array}{l}\text { Probability that a Small Bank is } \\
\text { Awarded a Share of the Security }\end{array}$} & 0.946 & 0.943 & 0.950 \\
\hline \multirow{2}{*}{$\begin{array}{l}\text { Highest Price } \\
\text { Submitted* }\end{array}$} & Large Banks & $\begin{array}{l}101.449 \\
(10.571)\end{array}$ & $\begin{array}{l}102.780 \\
(12.122)\end{array}$ & $\begin{array}{l}100.055 \\
(8.063)\end{array}$ \\
\hline & Small Banks & $\begin{array}{l}101.325 \\
(15.039)\end{array}$ & $\begin{array}{l}102.676 \\
(18.137)\end{array}$ & $\begin{array}{l}99.862 \\
(9.938)\end{array}$ \\
\hline \multirow{2}{*}{$\begin{array}{c}\text { Profit } \\
\text { Per Bank } \\
\text { (Million Euros) }\end{array}$} & Large Banks & $\begin{array}{c}1.322 \\
(0.311) \\
\end{array}$ & $\begin{array}{c}1.379 \\
(0.340) \\
\end{array}$ & $\begin{array}{c}1.278 \\
(0.284) \\
\end{array}$ \\
\hline & Small Banks & $\begin{array}{c}0.137 \\
(0.047)\end{array}$ & $\begin{array}{c}0.151 \\
(0.051)\end{array}$ & $\begin{array}{c}0.124 \\
(0.041)\end{array}$ \\
\hline \multirow{2}{*}{$\begin{array}{l}\text { Expected } \\
\text { Utility }\end{array}$} & Large Banks & $\begin{array}{l}-0.902 \\
(0.008)\end{array}$ & $\begin{array}{l}-0.889 \\
(0.008)\end{array}$ & $\begin{array}{l}-0.911 \\
(0.009)\end{array}$ \\
\hline & Small Banks & $\begin{array}{l}-0.433 \\
(0.015)\end{array}$ & $\begin{array}{l}-0.427 \\
(0.013)\end{array}$ & $\begin{array}{l}-0.436 \\
(0.016)\end{array}$ \\
\hline \multirow{2}{*}{$\begin{array}{l}\text { Percentage of } \\
\text { Issue Awarded } \\
\text { Subject to the } \\
\text { Winner's Curse }\end{array}$} & Large Banks & $\begin{array}{c}0.007 \\
(0.005)\end{array}$ & $\begin{array}{c}0.006 \\
(0.005)\end{array}$ & $\begin{array}{c}0.005 \\
(0.004)\end{array}$ \\
\hline & Small Banks & $\begin{array}{c}0.005 \\
(0.003)\end{array}$ & $\begin{array}{c}0.004 \\
(0.004)\end{array}$ & $\begin{array}{c}0.005 \\
(0.002)\end{array}$ \\
\hline \multirow{3}{*}{$\begin{array}{l}\text { Per Auction } \\
\text { Revenue } \\
\text { For Treasury } \\
\text { (Million Euros) }\end{array}$} & Total & $\begin{array}{l}1,659.410 \\
(623.409)\end{array}$ & $\begin{array}{l}1,668.581 \\
(588.977)\end{array}$ & $\begin{array}{l}1,649.922 \\
(627.637)\end{array}$ \\
\hline & $\begin{array}{l}\text { From Large } \\
\text { Banks }\end{array}$ & $\begin{array}{c}589.233 \\
(418.840)\end{array}$ & $\begin{array}{c}593.956 \\
(410.876)\end{array}$ & $\begin{array}{c}584.818 \\
(421.643)\end{array}$ \\
\hline & $\begin{array}{l}\text { From Small } \\
\text { Banks }\end{array}$ & $\begin{array}{l}1,070.177 \\
(330.616)\end{array}$ & $\begin{array}{l}1,074.625 \\
(327.996)\end{array}$ & $\begin{array}{l}1,065.104 \\
(335.754)\end{array}$ \\
\hline \multicolumn{2}{|c|}{$\begin{array}{l}\text { Total Revenue for Treasury } \\
\text { During the Sampling Period }\end{array}$} & $195,810.333$ & $100,114.858$ & $95,695.476$ \\
\hline
\end{tabular}

* Prices are expressed as a percentage of one Euro. Standard deviations are in parenthesis. 


\section{Graph 1 : Bid Functions}

( $N 1=5, N 2=15$, Other Exogenous Variables and Private Signals are taken at their means)

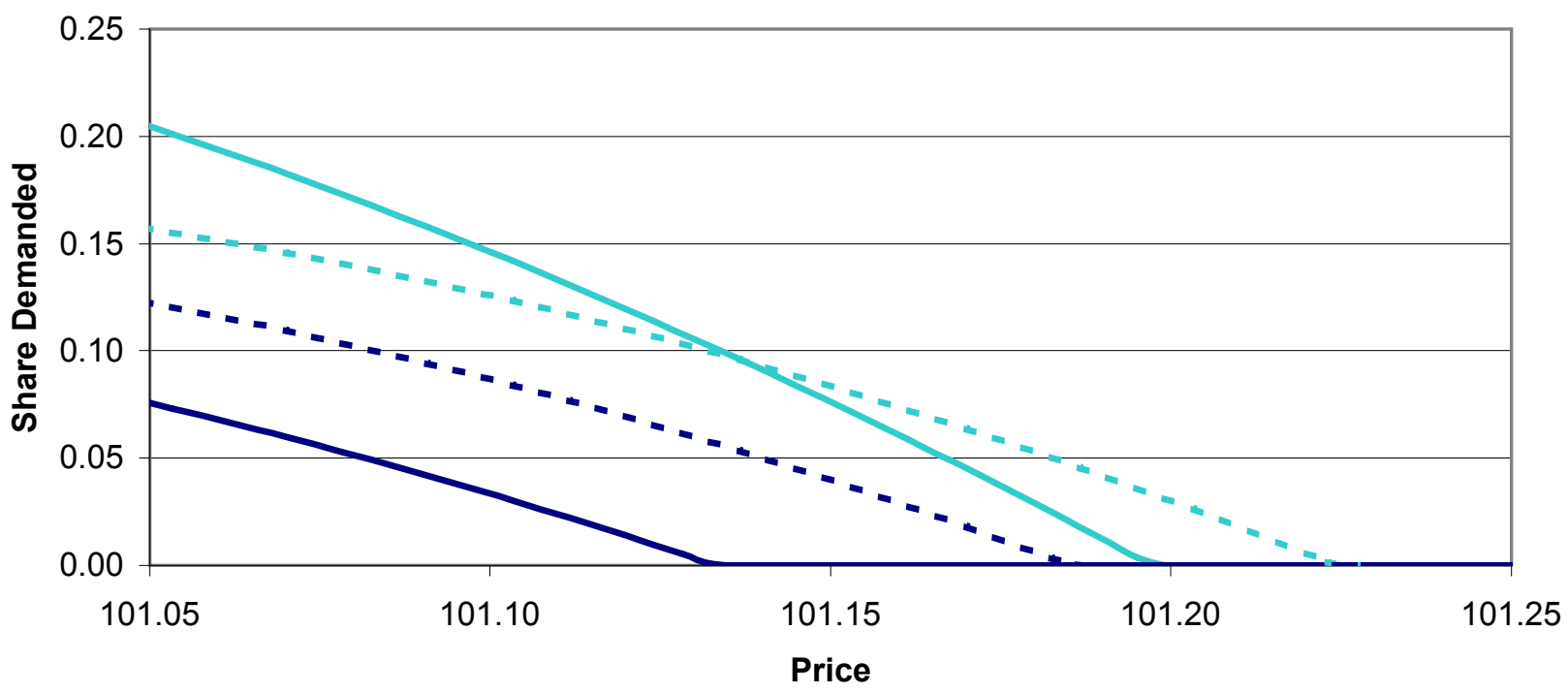

Large Firm Discriminatory - Small Firm Discriminatory

- - - Small Firm Uniform

\section{Graph 2}

Effect of Private Signals on Quantity Demanded by a

Large Firm in a Discriminatory Auction

(in Deviation from the Quantity Demanded for an Average Private Signal)

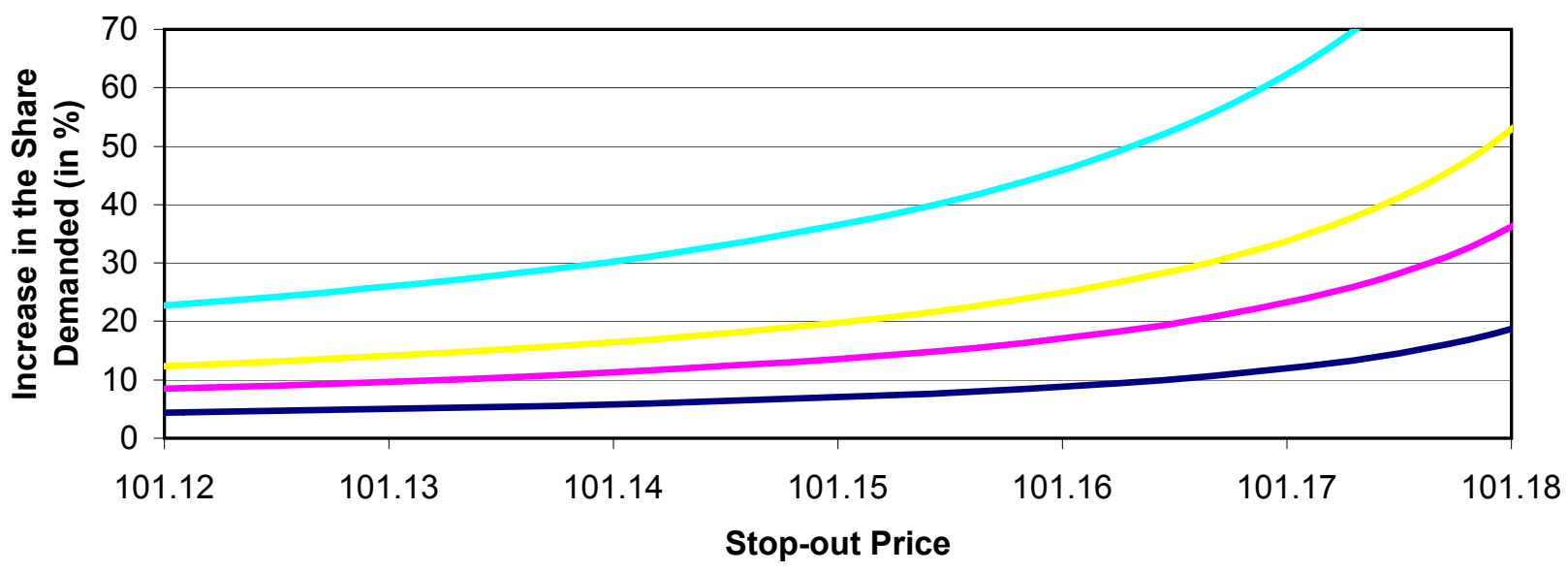

-Average + 0.5 Standard Deviation -Average +1 Standard Deviation Average +2 Standard Deviation -Average +3 Standard Deviation 